\title{
Simplified Lambert W-Function Math Equations When Applied to Photovoltaic Systems Modeling
}

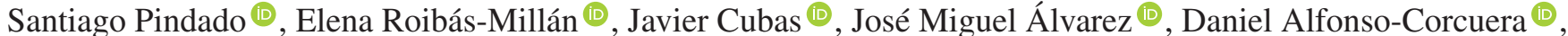 \\ Juan L. Cubero-Estalrrich ${ }^{(1)}$, Alejandro Gonzalez-Estrada ${ }^{(\circledR)}$, Marlon Sanabria-Pinzón ${ }^{\circledR}$, and Rocío Jado-Puente ${ }^{(1)}$
}

\begin{abstract}
In this article, simplified and easy-to-work-with equations for the Lambert $W$-function are derived. This function is widely used to solve equations related to photovoltaic systems. More specifically, this mathematical function represents a useful tool when modeling solar cells/panels performance (that is, the currentvoltage curve) by analytical approaches. However, the Lambert W-function has a complex solving process which might represent an unaffordable mathematical challenge for a great number of professionals/technicians in the photovoltaic industrial sector. Simple approximations for the Lambert W-function on both of its branches (positive and negative) are proposed in this article. The results of the present article show a simple but accurate way for photovoltaic systems modeling, even when these systems comprise a maximum power point tracking subsystem.
\end{abstract}

Index Terms-1-diode/2-resistor model, I-V curve, Lambert Wfunction, maximum power point tracking (MPPT), photovoltaic systems performance, solar cell, solar panel.

\section{INTRODUCTION}

$\mathbf{R}$ ENEWABLE energy plays a very important role in reducing fossil resources consumption [1], which is a present and urgent need for mankind due to problems, such as global warming, climate change and air pollution [2]. Among the different renewable energy sources, solar energy is probably the most relevant, as it is clean, safe, and unlimited [3], [4].

The figures can be overwhelming. In one year the amount of energy received from the sun is 10000 times larger than the world's energy consumption [4]. The installed photovoltaic power increased from $100.9 \mathrm{GW}$ in 2012 to $230 \mathrm{GW}$ in 2015 , reaching $400 \mathrm{GW}$ in 2017 [1], [5]. This rate of increase has been

Manuscript received September 13,2020; revised October 16, 2020 and December 7, 2020; accepted January 6, 2021. Paper 2020-SECSC-1403.R2, presented at the 2020 IEEE International Conference on Environment and Electrical Engineering and 2020 IEEE Industrial and Commercial Power Systems Europe, Madrid, Spain, Jun. 9-12, and approved for publication in the IEEE TRANSACTIONS ON INDUSTRY APPLICATIONS by the Renewable and Sustainable Energy Conversion Systems Committee of the IEEE Industry Applications Society. (Corresponding author: Santiago Pindado.)

The authors are with the Instituto de Microgravedad "Ignacio Da Riva" (IDR/UPM) Escuela Técnica Superior de Ingeniería Aeronáutica y del Espacio (ETSIAE), Universidad Politécnica de Madrid, 28040 Madrid, Spain (e-mail: santiago.pindado@upm.es; elena.roibas@upm.es; j.cubas@upm.es; jm.alvarez@upm.es; daniel.alfonso.corcuera@alumnos.upm.es; jl.cubero@ alumnos.upm.es; alejandro.gonzalez.estrada@alumnos.upm.es; ms.sanabria@ alumnos.upm.es; rocio.jado.puente@alumnos.upm.es).

Color versions of one or more of the figures in this article are available at https://doi.org/10.1109/TIA.2021.3052858.

Digital Object Identifier 10.1109/TIA.2021.3052858 possible due to a new generation of solar cells that allow production growth while reducing costs and environmental impact [6].

Modeling has become the key for photovoltaic system design and development, as it allows proper and accurate energy production forecasts [7]. The modeling of these photovoltaic systems (solar cells or solar panels) is normally carried out by using equivalent circuit models, whose equations are quite challenging as they are mathematically implicit expressions. Nevertheless, in the last decade the Lambert W-function has been revealed as a powerful tool to solve these equations.

The aim of the present article is to derive simple expressions for the Lambert W-function, which is commonly used in photovoltaic systems, and describe how this function is required to solve equations related to these systems. The proposed expressions were derived by fitting well-known mathematical equations (polynomials, exponential functions, hyperbolic functions) to points on the Lambert $\mathrm{W}$-function calculated numerically with the highest available accuracy. The work carried out in the IDR/UPM Institute has prompted the authors to carry out the present article, as simple solutions to analyze solar panel behavior are required when developing spacecraft missions in a concurrent design facility [[8]-[11]], or analyzing thermoelectric coupled behavior [12].

The innovation offered by the present article is to derive very simple expressions for the Lambert $\mathrm{W}$-function that can be solved quickly with a pocket calculator, to model a photovoltaic systems performance (or that can be easily programmed for complex simulations, such as the thermo-electric analysis of space systems).

The rest of this article is organized as follows. In Section II, the Lambert W-Function is described in relation to its use in photovoltaic systems modeling. In Section III, the different mathematical expressions derived to estimate the Lambert Wfunction branches $W_{-1}, W_{0}{ }^{+}$, and $W_{0}{ }^{-}$, are defined, together with their accuracy. In Section IV, the results of the use of these equations are shown. Finally, the conclusions is summarized in Section V.

\section{LAMBERT W-FUNCTION}

The Lambert W-function has proven to be a very useful tool for solving equations related to: time-delay differential problems, control stability, flight dynamics of projectiles, enzyme kinetics, and solid-state electronics modeling problems 


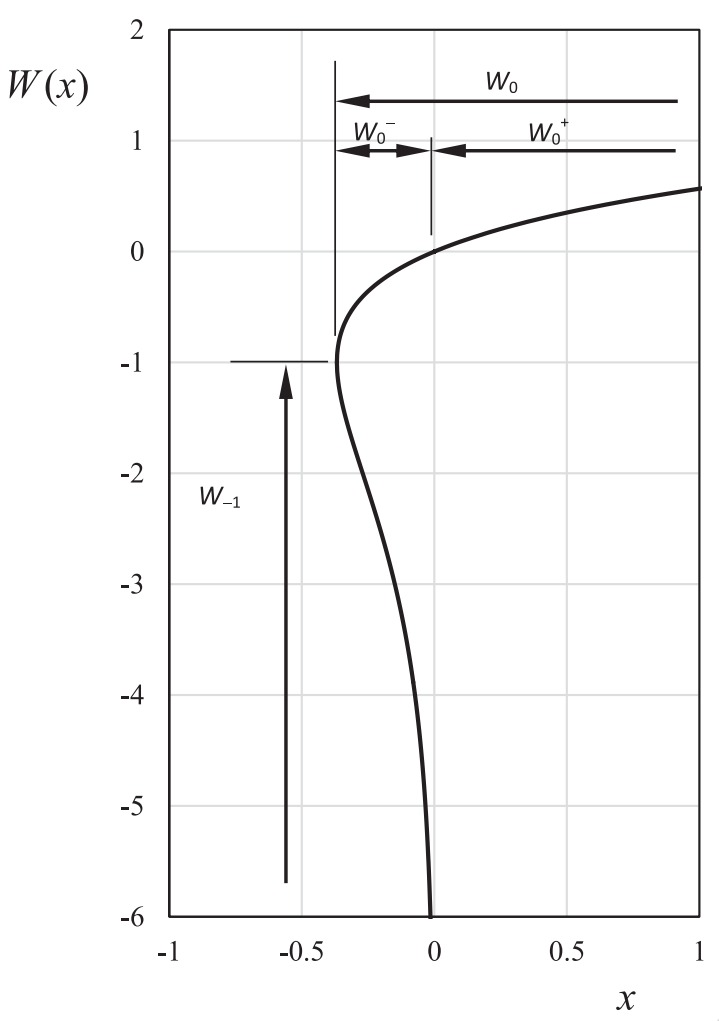

Fig. 1. Lambert W-function. The different branches are indicated in the graph.

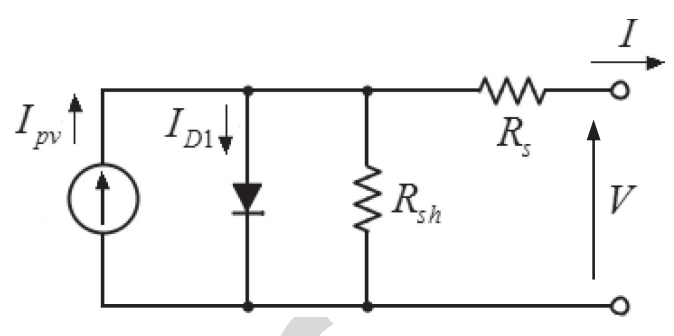

Fig. 2. Solar cell/panel 1-diode/2-resistor equivalent circuit.

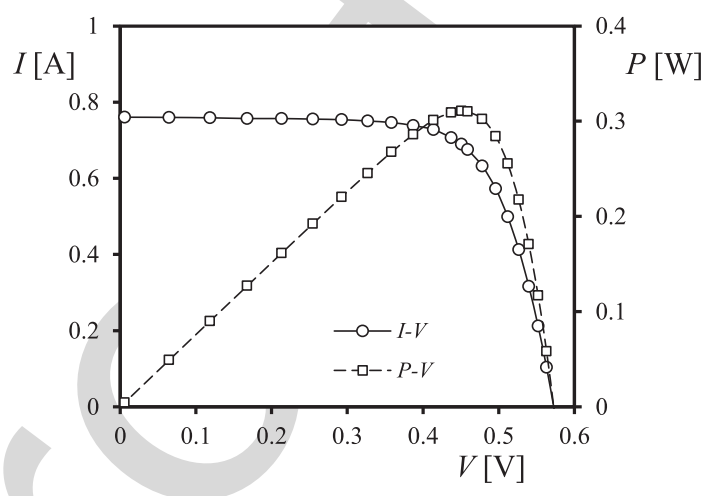

Fig. 3. $I-V$ (current-voltage) and $P-V$ (power-voltage) curves of a Si solar cell.

model (see Fig. 2) is the following [23]:

$$
I=I_{p v}-I_{0}\left[\exp \left(\frac{V+I R_{s}}{n a V_{T}}\right)-1\right]-\frac{V+I R_{s}}{R_{s h}}
$$

in which the first term is the photocurrent, the second term is the current through the diode, and the third term represents the current through the shunt resistor. $V_{T}$ is the thermal voltage ( $V_{T}=\kappa T / q ; \kappa$ being the Boltzmann constant, $T$ the temperature, and $q$ the electron charge), $a$ is the ideality factor of the diode and $n$ is the number of series-connected cells within the panel.

Working with the above equation is not a simple task, as the parameters involved in the equation $\left(I_{p v}, I_{0}, a, R_{s}\right.$, and $\left.R_{s h}\right)$ should be calculated to fit the equation to a specific $I-V$ curve (see Fig. 3), which depends on both the solar irradiance, $G$, on the cell/panel and its temperature, $T$.

Equation (1) is an implicit mathematical expression. Therefore, for a given value of the output voltage $V$ the calculation of the corresponding output current $I$ is not immediate, which makes an iteration process necessary. Nevertheless, different methodologies have been developed to work with this equation depending on the available information [24]-[30].

Among the aforementioned methodologies developed to fit equation (1) to a specific $I-V$ curve, it is possible to mention numerical and analytical ones. Numerical techniques fit the equation by using different algorithms. These procedures obtain very accurate results. However, they require both high computational resources and skill. Additionally, they might be a drawback if coupled calculations are required (thermoelectric calculations of the behavior of solar panels in space are a good example of this sort of calculation [12]). 
On the other hand, analytical procedures are simpler and based on limited information from the $I-V$ curve, its characteristic points are as follows [31], [32]:

1) short circuit current $I_{\mathrm{sc}}$;

2) open circuit voltage $V_{\text {oc }}$;

3) current and voltage at maximum power point (MPP) $I_{\mathrm{mp}}$ and $V_{\mathrm{mp}}$.

Analytical methodologies are not as accurate as the numerical ones, but can offer quick and satisfactory results.

If the characteristic points of the $I-V$ curve are known for certain values of sun irradiance $G$ and the temperature $T$, it is possible to calculate four of the parameters of the model in relation to the fifth one, which is the ideality factor, $a$ [23], [33]

$$
\begin{aligned}
I_{p v}= & \frac{R_{s h}+R_{s}}{R_{s h}} I_{\mathrm{sc}} \\
I_{0}= & \frac{\left(R_{s h}+R_{s}\right) I_{\mathrm{sc}}-V_{\mathrm{oc}}}{R_{s h} \exp \left(\frac{V_{\mathrm{oc}}}{n a V_{T}}\right)} \\
& \times \frac{n a V_{T} V_{\mathrm{mp}}\left(2 I_{\mathrm{mp}}-I_{\mathrm{sc}}\right)}{\left(\begin{array}{l}
\left(V_{\mathrm{mp}} I_{\mathrm{sc}}+V_{\mathrm{oc}}\left(I_{\mathrm{mp}}-I_{\mathrm{sc}}\right)\right)\left(V_{\mathrm{mp}}-I_{\mathrm{mp}} R_{s}\right) \\
-n a V_{T}\left(V_{\mathrm{mp}} I_{\mathrm{sc}}-V_{\mathrm{oc}} I_{\mathrm{mp}}\right)
\end{array}\right)} \\
= & \exp \left(\frac{V_{\mathrm{mp}}+I_{\mathrm{mp}} R_{s}-V_{\mathrm{oc}}}{n a V_{T}}\right) \\
R_{s h}= & \frac{\left(V_{\mathrm{mp}}-I_{\mathrm{mp}} R_{s}\right)\left(V_{\mathrm{mp}}-R_{s}\left(I_{\mathrm{sc}}-I_{\mathrm{mp}}\right)-n a V_{T}\right)}{\left(V_{\mathrm{mp}}-I_{\mathrm{mp}} R_{s}\right)\left(I_{\mathrm{sc}}-I_{\mathrm{mp}}\right)-n a V_{T} I_{\mathrm{mp}}}
\end{aligned}
$$

Therefore, once the ideality factor $a$, has been estimated (according to its value within the bracket [1, 1.5] [34], [35]), it is possible to sequentially obtain $R_{s}$ [from (5)], $R_{s h}$ [from (6)], $I_{0}$ [from (4)], and $I_{\mathrm{pv}}$ [from (3)]. Finally, the output current $I$ can be defined for each value of the output voltage $V$ by means of an iterative process, or the following equation [36]:

$$
\begin{aligned}
I= & \frac{R_{s h}\left(I_{\mathrm{pv}}+I_{0}\right)-V}{R_{s h}+R_{s}} \\
& -\frac{n a V_{T}}{R_{s}} W_{0}\left(\frac{R_{s h} R_{s} I_{0}}{n a V_{T}\left(R_{s h}+R_{s}\right)}\right. \\
& \left.\exp \left(\frac{R_{s h} R_{s}\left(I_{\mathrm{pv}}+I_{0}\right)+R_{s h} V}{n a V_{T}\left(R_{s h}+R_{s}\right)}\right)\right)
\end{aligned}
$$

where $W_{0}$ is the positive branch of the Lambert W-function. In fact, the right-side sub-branch $W_{0}{ }^{+}$is the one required.

Alternatively, solving equation (5) to obtain the value of $R_{s}$ requires an iterative process, this parameter can be obtained from [37]

$$
R_{s}=A\left(W_{-1}(B \exp (C))-(D+C)\right)
$$

where $W_{-1}$ is the negative branch of the Lambert W-function and

$$
\begin{aligned}
& A=\frac{n a V_{T}}{I_{\mathrm{mp}}} \\
& B=-\frac{V_{\mathrm{mp}}\left(2 I_{\mathrm{mp}}-I_{\mathrm{sc}}\right)}{V_{\mathrm{mp}} I_{\mathrm{sc}}+V_{\mathrm{oc}}\left(I_{\mathrm{mp}}-I_{\mathrm{sc}}\right)}
\end{aligned}
$$

$$
\begin{aligned}
C & =-\frac{2 V_{\mathrm{mp}}-V_{\mathrm{oc}}}{n a V_{T}}+\frac{V_{\mathrm{mp}} I_{\mathrm{sc}}-V_{\mathrm{oc}} I_{\mathrm{mp}}}{V_{\mathrm{mp}} I_{\mathrm{sc}}+V_{\mathrm{oc}}\left(I_{\mathrm{mp}}-I_{\mathrm{sc}}\right)} \\
D & =\frac{V_{\mathrm{mp}}-V_{\mathrm{oc}}}{n a V_{T}}
\end{aligned}
$$

\section{B. Explicit Models Solved With the Lambert W-Function}

There are several explicit models to analyze the currentvoltage performance of a solar cell/panel [38], [39]. Although these approximations do not preserve any physical aspect of the photovoltaic conversion process, they are interesting and accurate enough to generate new works from time to time [40]. Among the explicit models, the ones that reach a solution based on the Lambert W-function are as follows.

1) El-Tayyan's model

$$
I=I_{s c}-C_{1} \exp \left(-\frac{V_{\mathrm{oc}}}{C_{2}}\right)\left(\exp \left(\frac{V}{C_{2}}\right)-1\right)
$$

where

$$
C_{1}=\frac{I_{\mathrm{sc}}}{1-\exp \left(-\frac{V_{\mathrm{oc}}}{C_{2}}\right)}
$$

and, if $V_{o c} / C_{2}>>1$

$$
C_{2}=\frac{V_{\mathrm{mp}}-V_{\mathrm{oc}}}{W_{-1}\left(\left(1-\frac{V_{\mathrm{oc}}}{V_{\mathrm{mp}}}\right)\left(\frac{I_{\mathrm{mp}}}{I_{\mathrm{sc}}}\right)\right)} .
$$

2) Karmalkar and Haneefa's model

$$
\frac{I}{I_{\mathrm{sc}}}=1-(1-\gamma)\left(\frac{V}{V_{\mathrm{oc}}}\right)-\gamma\left(\frac{V}{V_{\mathrm{oc}}}\right)^{m}
$$

where

$$
\begin{aligned}
& \gamma=\frac{2\left(\frac{I_{\mathrm{mp}}}{I_{\mathrm{sc}}}\right)-1}{(m-1)\left(\frac{V_{\mathrm{mp}}}{V_{\mathrm{oc}}}\right)^{m}} \\
& m=\frac{W_{-1}\left(-\left(\frac{V_{\mathrm{oc}}}{V_{\mathrm{mp}}}\right)^{\frac{1}{K}}\left(\frac{1}{K}\right) \ln \left(\frac{V_{\mathrm{mp}}}{V_{\mathrm{oc}}}\right)\right)}{\ln \left(\frac{V_{\mathrm{mp}}}{V_{\mathrm{oc}}}\right)}+\frac{1}{K}+1
\end{aligned}
$$

with

$$
K=\frac{1-\left(\frac{I_{\mathrm{mp}}}{I_{\mathrm{sc}}}\right)-\left(\frac{V_{\mathrm{mp}}}{V_{\mathrm{oc}}}\right)}{2\left(\frac{I_{\mathrm{mp}}}{I_{\mathrm{sc}}}\right)-1} .
$$

3) Das' model

$$
\frac{I}{I_{s c}}=\frac{1-\left(\frac{V}{V_{\mathrm{oc}}}\right)^{k}}{1+h\left(\frac{V}{V_{\mathrm{oc}}}\right)}
$$

where

$$
k=\frac{W_{-1}\left(\left(\frac{I_{\mathrm{mp}}}{I_{\mathrm{sc}}}\right) \ln \left(\frac{V_{\mathrm{mp}}}{V_{\mathrm{oc}}}\right)\right)}{\ln \left(\frac{V_{\mathrm{mp}}}{V_{\mathrm{oc}}}\right)}
$$




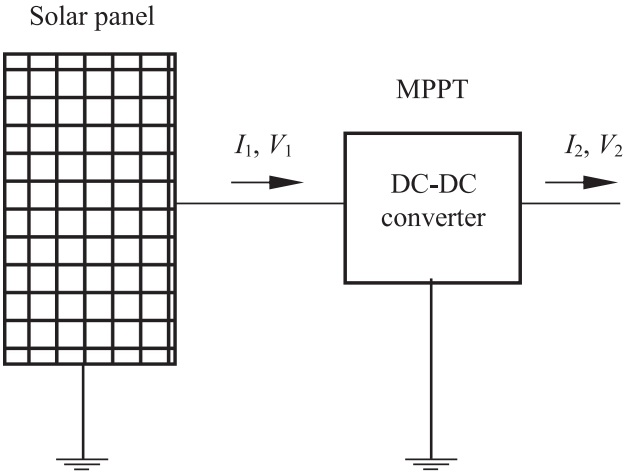

Fig. 4. Sketch of a solar panel connected to a dc-dc converter that works as MPPT.

$$
h=\left(\frac{V_{\mathrm{oc}}}{V_{\mathrm{mp}}}\right)\left(\frac{I_{\mathrm{sc}}}{I_{\mathrm{mp}}}-\frac{1}{k}-1\right) .
$$

\section{Modeling Maximum Power Point Tracking (MPPT) Performance With the Lambert W-Function}

The ambient conditions in which a solar panel works (temperature and solar irradiance), have a relevant effect on its performance [12], [37], [41]. This problem has led to the development of MPPT methods, in order to fix the working point of the solar panel at the MPP of the $I-V$ curve (see Fig. 3), no matter the level of the irradiance on the solar panel or the temperature of its cells.

Among the different electronic architectures on which MPPT systems are based, dc-dc converters should be mentioned [42][45]. In this MPPT, the voltage at the primary winding (where the solar panel is connected, see Fig. 4) is changed in relation to the voltage at the secondary winding, to reach the aforementioned MPP [46]-[49]. Additionally, it should be noted that the process of setting the voltage at the primary winding of the $\mathrm{dc}-\mathrm{dc}$ converter at the MPP of a solar panel, in relation to the irradiance and temperature conditions, is not an immediate task, since there are many procedures available in [50]-[57].

The behavior of a solar panel can be defined by means of its efficiency, $\eta$, defined as the ratio between the input and the output power

$$
\eta=\frac{V_{2} I_{2}}{V_{1} I_{1}}
$$

where $V_{1}$ is the input voltage, $V_{2}$ is the output voltage, $I_{1}$ is the input current, and $I_{2}$ is the output current (all variables in relation to the MPPT, see Fig. 4).

The efficiency $\eta$ of the three dc-dc converters used in the UPMSat-2 satellite power distribution subsystem is plotted in relation to the output current $I_{2}$ in Fig. 5. These converters are as follows.

1) $\pm 15 \mathrm{~V}$ converter: It converts the bus voltage into +15 and $-15 \mathrm{~V}$ (this converter has two output voltage levels in relation to ground).

2) $+5 \mathrm{~V}$ converter: It converts $+15 \mathrm{~V}$ voltage into $+5 \mathrm{~V}$.

3) $+3.3 \mathrm{~V}$ converter: It converts $+15 \mathrm{~V}$ voltage into $+3.3 \mathrm{~V}$.

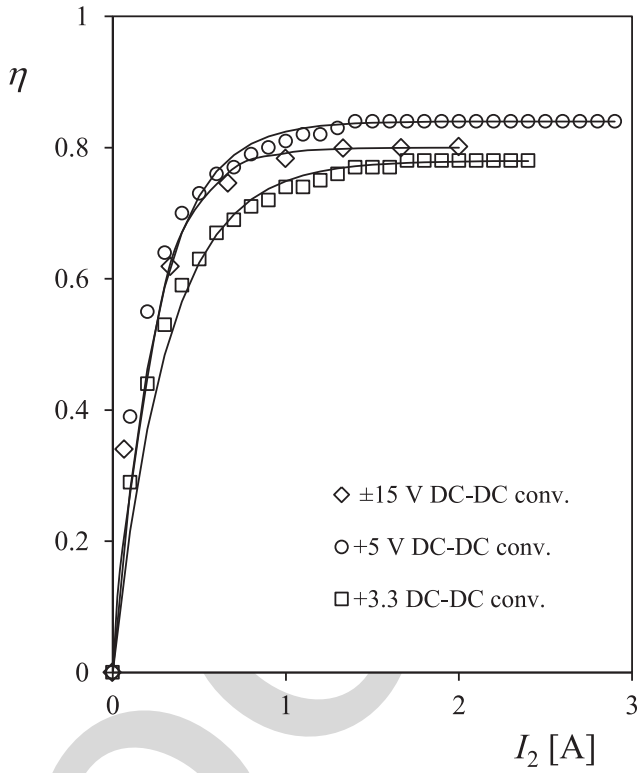

Fig. 5. Efficiency $\eta$ of the UPMSat-2 power distribution subsystem dc-dc converters in relation to the output current $I_{2}$. The fitting of (24) to the three data sets have also been plotted as solid lines.

It is possible to fit each one of these curves to the following equation:

$$
\eta=\eta_{\max }\left(1-\exp \left(g\left(I_{2}\right)\right)\right)
$$

where $\eta_{\max }$ is the maximum value of the efficiency and $f\left(I_{2}\right)$ is a function (normally, a polynomial) which depends on the output current, $I_{2}$. If the simplest approach is selected:

$$
g\left(I_{2}\right)=-\frac{I_{2}}{I_{\mathrm{ch}}}
$$

Equation (24) becomes the well-known solution of a first order system. In the above equation, $I_{\mathrm{ch}}$ is a characteristic current.

In Fig. 5, (24) has been fitted to the three sets of data, the values of the maximum efficiency and the characteristic current being: $\eta=0.8$ and $I_{\mathrm{ch}}=0.22 \mathrm{~A}( \pm 15 \mathrm{~V}$ converter $) ; \eta=0.84$ and $I_{c h}=0.25 \mathrm{~A}(+5 \mathrm{~V}$ converter $) ;$ and $\eta=0.78$ and $I_{c h}=0.31$ $\mathrm{A}(+3.3 \mathrm{~V}$ converter $)$.

Once the output voltage, $V_{2}$, the input variables of the MPPT ( $I_{1}$ and $V_{1}$, i.e., the MPP), and the behavior of the MPPT ( $\eta$ and $\left.I_{\mathrm{ch}}\right)$ are known, the problem that needs to be solved is finding the correct value of the output current $I_{2}$. The following implicit equation defines this problem:

$$
I_{2}=\frac{V_{1} I_{1}}{V_{2}} \eta_{\max }\left(1-\exp \left(-\frac{I_{2}}{I_{\mathrm{ch}}}\right)\right) .
$$

As the equation from the solar panel 1-D/2-R equivalent circuit model, the above equation can be defined by using the left side of the Lambert W-function positive branch

$$
I_{2}=I_{\mathrm{ch}}\left(\lambda+W_{0}^{-}(-\lambda \exp (-\lambda))\right)
$$

where

$$
\lambda=\frac{V_{1} I_{1}}{V_{2} I_{\mathrm{ch}}} \eta_{\max }
$$




\section{LAMBERT W-FUnCTION SIMPLE EQUATIONS}

Once the problems in which the Lambert W-function needs to be accurately estimated were identified (see previous sections), they can be summarized as follows.

1) $1-D / 2-R$ equivalent circuit model

a) Solving equation (8) to obtain the value of $R_{s}$, by using the negative branch of the Lambert W-function, $W_{-1}$.

b) Solving equation (7) to obtain the output current $I$ in relation to the output voltage $V$ by using the right-side sub-branch of the positive branch of the Lambert Wfunction $\mathrm{W}_{0}{ }^{+}$.

2) El-Tayyan, Karmalkar and Haneefa, and Das explicit models: solving (15), (18), and (21) by using the negative branch of the Lambert W-function $W_{-1}$.

3) MPPT (based on dc-dc converters) performance: Solving equation (27) by using the left- sub-branch of the positive branch of the Lambert W-function $W_{0}{ }^{-}$.

A thorough review of the available literature was carried out, in order to obtain sufficiently large data to derive accurate mathematical expressions for the Lambert W-function within the appropriate $x$ variable range (where this function needs to be calculated).

The relevant data (i.e., the five parameters of the 1-diode/2resistors model $I_{\mathrm{pv}}, I_{0}, a, R_{s}$, and $R_{s h}$, the number of cells seriesconnected, $n$, the temperature in which the $I-V$ curve is measured or calculated $T$ and the four characteristic points $I_{\mathrm{sc}}, V_{\mathrm{oc}}, I_{\mathrm{mp}}$, and $V_{\mathrm{mp}}$ ), from 89 different photovoltaic devices (mostly solar panels), were found.

\section{A. Lambert W-Function for Solving the 1-D/2-R Equivalent Circuit Model Implicit Equation}

If we go to (7), this allows us to calculate the current for a variable $x$ that is written in relation to the aforementioned five parameters of the 1-diode/2-resistors model, the number of cells series-connected, the temperature and the output voltage $V$

$$
x=f\left(I_{\mathrm{pv}}, I_{0}, a, R_{s}, R_{s h}, n, T, V\right) .
$$

Bearing in mind that, when evaluating the performance of a photovoltaic device, two extremes of the above variable $x$ arise at short circuit $(V=0)$ and open circuit $\left(V=V_{\mathrm{oc}}\right)$ points, it is possible to define a characteristic interval for evaluating the Lambert $\mathrm{W}$-function in relation to (7). The values of the Lambert W-function $W_{0}{ }^{+}$calculated at each point (29) with the data from each photovoltaic device found in the available literature, at $V=0$ and $V=V_{\mathrm{oc}}$, are shown in Fig. 6. Based on these points, included in the bracket $\left[10^{-20}, 10^{-5}\right]$, the following approximation is proposed:

$$
\begin{aligned}
& W_{0}^{+}(x)=x \\
& -\exp \left(4.123 \cdot 10^{-6} \ln (x)^{2}+2.0001 \ln (x)+1.64 \cdot 10^{-4}\right) .
\end{aligned}
$$

The above equation has also been plotted in Fig. 7. It should be noted that this equation has $1.4 \%$ error for $x=0.1$, the accuracy being improved for lower values of $x$. For larger values of $x$ it is recommended to use the approximation proposed by Barry $e t$ al. [22] (see Appendix), as shown in Fig. 6.

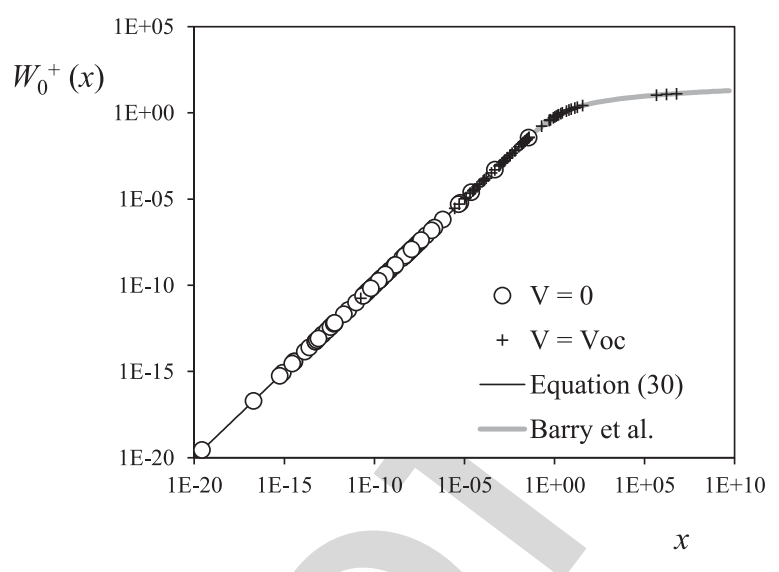

Fig. 6 Lambert W-function, $W_{0}+$ from (7) calculated at $V=0$ and $V=V_{\text {oc }}$ for the solar cells/solar panel data found in the available literature. The approximated (30) is also plotted in the graph.

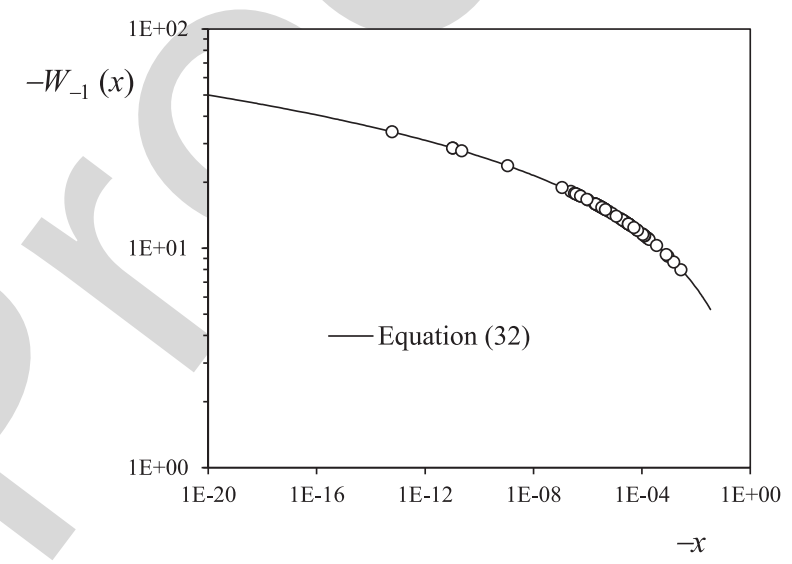

Fig. 7. Lambert W-function, $W_{-1}$ from (8) calculated for the solar cells/solar panel data found in the available literature (open circles). The approximated (32) is also plotted in the graph.

\section{B. Lambert W-Function for Solving the Series Resistor Implicit Equation From the Analytcal Solution of the 1-D/2-R Equivalent Circuit Model}

The negative branch of the Lambert $\mathrm{W}$-function, $W_{-1}$, allows the user to calculate the series resistor of the 1-diode/2-resistor model $R_{s}$ in relation to the characteristic points, the number of cells that are series-connected, the ideality factor and the temperature (8). Therefore, $W_{-1}$ is required to be evaluated at

$$
x=f\left(I_{\mathrm{sc}}, I_{\mathrm{mp}}, V_{\mathrm{oc}}, V_{\mathrm{mp}}, a, n, T\right) .
$$

In Fig. 7, the values of $W_{-1}$, calculated at the values of the above variable $x$ resulting from the solar cells and solar panel data found in the literature, are plotted. The bracket in which the Lambert W-function $W_{-1}$ needs to be evaluated is $\left[-10^{-3}\right.$, $\left.-10^{-20}\right]$. The following simple expression is proposed for these estimations:

$$
\begin{aligned}
W_{-1}(x)= & 2.4978 \cdot 10^{-5} \ln (-x)^{3} \\
& +2.8111 \cdot 10^{-3} \ln (-x)^{2} \\
& +1.1299 \ln (-x)-1.4733 .
\end{aligned}
$$




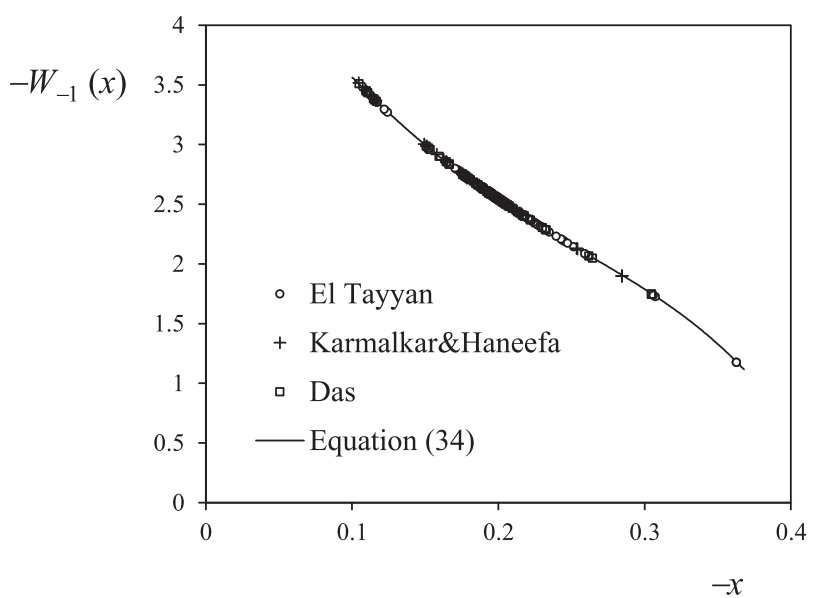

Fig. 8. Lambert W-function, $W_{-1}$ from (15), (18), and (21) calculated for the solar cells/solar panel data found in the available literature (open circles, crosses, and open squares). The approximated (34) is also plotted in the graph.

This equation is also plotted in Fig. 7. The maximum error in (32) was proven to be below $0.4 \%$, within the mentioned bracket.

\section{Lambert W-Function for Solving the Equations From El-Tayyan, Karmalkar and Haneefa, and Das Explicit Models}

With regard to the explicit models that need the Lambert W-function (15), (18), and (21), the values of this function are plotted in Fig. 8, in relation to the corresponding figures of variable $x$

$$
x=f\left(I_{\mathrm{sc}}, I_{\mathrm{mp}}, V_{\mathrm{oc}}, V_{\mathrm{mp}}\right)
$$

for each photovoltaic device found in the available literature. Based on these points, the following equation is proposed for the Lambert $\mathrm{W}$-function, $W_{-1}$, in the bracket $[-0.364,-0.1]$

$$
\begin{aligned}
& W_{-1}(x) \\
& =248.42 x^{4}+134.24 x^{3}+4.4258 x^{2}-14.629 x-4.9631 .
\end{aligned}
$$

The above equation has less than $1.6 \%$ error within the mentioned bracket.

\section{Lambert W-Function for Solving the Implicit Equation of} the MPPT Model

The left side of the Lambert W-function positive branch, required to solve the MPPT equation (see Section I-DD), needs to be evaluated at

$$
x=f\left(V_{1}, I_{1}, V_{2}, I_{\mathrm{ch}}, \eta_{\max }\right)
$$

along with (27) and (28). The following mathematical expressions are proposed to approach the aforementioned left side of the Lambert W-function positive branch

$$
\begin{aligned}
W_{0}^{-}(x)= & x ; x \in\left[-8 \cdot 10^{-3}, 0\right] \\
W_{0}^{-}(x)= & 3.50621 x^{3}-0.7188 x^{2}+1.0104 x \\
& x \in\left[-2.15 \cdot 10^{-1},-8 \cdot 10^{-3}\right]
\end{aligned}
$$
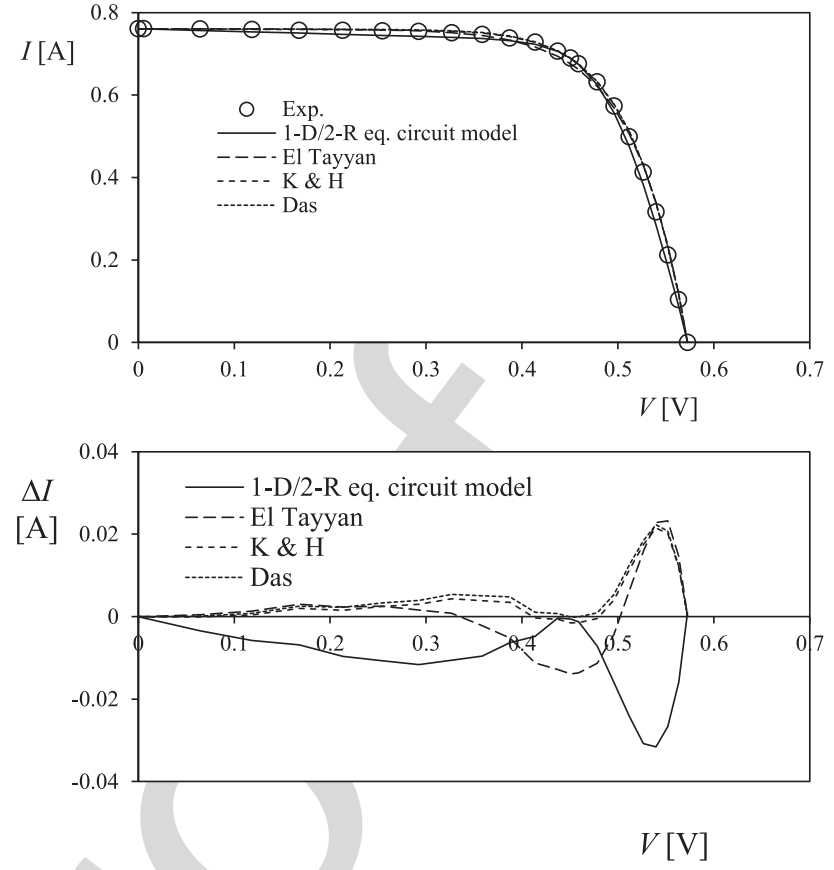

Fig. 9. RTC France solar cell [58]. 1-D/2-R equivalent circuit model and El Tayyan, Karmalkar and Haneefa, and Das explicit models fitted to the testing results (Exp.) (top). Error of the different models in relation to the testing results, $\Delta I=I-I_{\exp }$ (bottom).

TABLE I

NUMBER OF SERIES-CONNECTED CELlS AND CHARACTERISTIC POINTS FROM RTC France Solar CEll and PhotowatT PWP 201 Solar PANEL

\begin{tabular}{|c|c|c|}
\hline & RTC France & $\begin{array}{c}\text { Photowatt } \\
\text { PWP 201 }\end{array}$ \\
\hline$n$ & 1 & 36 \\
\hline$I_{s c}[\mathrm{~A}]$ & 0.7605 & 1.0320 \\
\hline$I_{m p}[\mathrm{~A}]$ & 0.6894 & 0.9255 \\
\hline$V_{m p}[\mathrm{~V}]$ & 0.4507 & 12.493 \\
\hline$V_{o c}[\mathrm{~V}]$ & 0.5727 & 16.778 \\
\hline
\end{tabular}

$$
\begin{array}{r}
W_{0}^{-}(x)=1.56322\left(x+e^{-1}\right)^{\frac{1}{2.4}}-1 \\
x \in\left[-e^{-1},-2.15 \cdot 10^{-1}\right] .
\end{array}
$$

Equations (36)-(38) have an error below $0.8 \%, 0.82 \%$ and $1.86 \%$, respectively.

\section{RESULTS AND DISCUSSION}

\section{A. Modeling Solar Cells/Panels}

In order to check the expressions for the Lambert W-function obtained in the previous section, the well-known RTC France solar cell and Photowatt PWP 201 solar panel $I-V$ curves from Easwarakhanthan et al. [58] were used (see Figs. 9 and 10). Since the publication of this article, these curves have become the standard for checking photovoltaic performance models and parameter extraction procedures [59]-[69]. In Table I, the number of series-connected cells, $n$, and the characteristic points of both photovoltaic devices are included. 

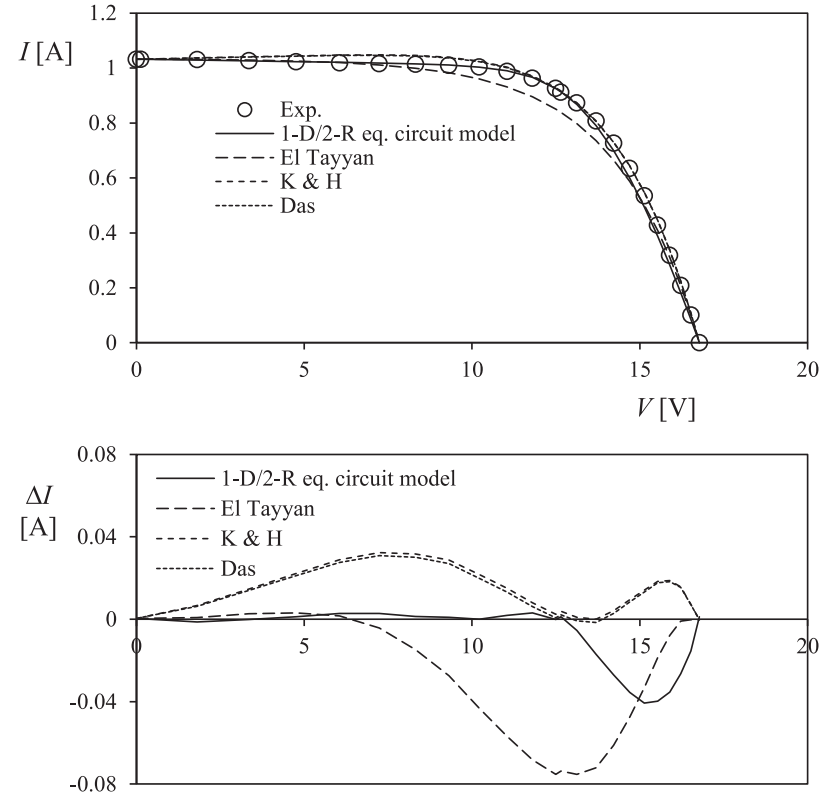

$V[\mathrm{~V}]$

Fig. 10. Photowatt PWP 201 solar panel [58]. 1-D/2-R equivalent circuit model and El Tayyan, Karmalkar and Haneefa, and Das explicit models fitted to the testing results (Exp.). Error of the different models in relation to the testing results, $\Delta I=I-I_{\exp }$ (bottom).

TABLE II 1-D/2-R EQuivalent Circuit Model FitTed to the RTC FRANCE SOLAR CELl $I-V$ CURVE. PARAMETERS EXTRACTED IN THE PRESENT ARTICLE AND IN EASWARAKHANTHAN et $a l$. [58]

\begin{tabular}{|c|c|c|}
\hline & \multicolumn{2}{|c|}{ RTC France solar cell } \\
\hline & $\begin{array}{c}\text { Easwrakhanthan } \\
\text { et al. [58], [70] }\end{array}$ & $\begin{array}{c}\text { Present } \\
\text { work }\end{array}$ \\
\hline$a$ & 1.4837 & 1 \\
\hline$I_{p v}[\mathrm{~A}]$ & $7.608 \cdot 10^{-01}$ & $7.638 \cdot 10^{-01}$ \\
\hline$I_{0}[\mathrm{~A}]$ & $3.223 \cdot 10^{-07}$ & $2.692 \cdot 10^{-10}$ \\
\hline$R_{s}[\Omega]$ & $3.640 \cdot 10^{-02}$ & $6.977 \cdot 10^{-02}$ \\
\hline$R_{s h}[\Omega]$ & $5.376 \cdot 10^{+01}$ & $1.616 \cdot 10^{+01}$ \\
\hline RMSE $[\mathrm{A}]$ & $6.251 \cdot 10^{-03}$ & $1.401 \cdot 10^{-02}$ \\
\hline
\end{tabular}

In Tables II and III, the parameters related to the 1-D/2-R equivalent circuit model fitted to the mentioned $I-V$ curves are included. These parameters were first extracted by selecting a reasonable value for the ideality factor, $a=1$, and then by using (8) to (12), (6), (4), and (3), combined with (32), to solve the Lambert W-function in (6). Taking the extracted values of Tables II and III, (7) was solved with the help of the Lambert W-function in (30), to obtain the output current $I$ as a function of the output voltage $V$. The results have been included as a solid line in Figs. 9 and 10. It can be observed that the results obtained match those from testing. The error with regard to the testing results $\Delta I$ is plotted in the bottom graphs of these figures, its maximum values being reduced in relation to $I_{\mathrm{mp}}$ : $1.7 \%$ (RTC) and $0.3 \%$ (PWP 201) for output voltages lower than $V_{\mathrm{mp}}$, and $4.6 \%$ (RTC) and 4.4\% (PWP 201) for output voltages larger than $V_{\mathrm{mp}}$. Additionally, it should be noted that, logically,
TABLE III

1-D/2-R Equivalent Circuit Model Fitted to the Photowatt PWP 201 Solar Panel $I-V$ CuRve. Parameters Extracted in the Present ARTICLE AND IN EASWARAKHANTHAN et al. [58]

\begin{tabular}{|c|c|c|}
\hline & \multicolumn{2}{|c|}{ Photowatt PWP 201 solar panel } \\
\hline & $\begin{array}{c}\text { Easwrakhanthan } \\
\text { et al. [58], [70] }\end{array}$ & $\begin{array}{c}\text { Present } \\
\text { work }\end{array}$ \\
\hline$a$ & 1.3458 & 1 \\
\hline$I_{p v}[\mathrm{~A}]$ & 1.0318 & 1.0358 \\
\hline$I_{0}[\mathrm{~A}]$ & $3.2876 \cdot 10^{-06}$ & $4.1626 \cdot 10^{-08}$ \\
\hline$R_{s}[\Omega]$ & 1.2057 & 1.9815 \\
\hline$R_{s h}[\Omega]$ & $5.4945 \cdot 10^{+02}$ & $5.4292 \cdot 10^{+02}$ \\
\hline RMSE $[\mathrm{A}]$ & $7.805 \cdot 10^{-03}$ & $1.799 \cdot 10^{-02}$ \\
\hline
\end{tabular}

TABLE IV

PARAMETERS OF El TAYYAN, KARMALKAR AND HANEEFA, AND DAS EXPLicIT Models, FitTed to RTC France Solar CELl AND Photowatt PWP 201 SOLAR PANEL EXPERIMENTAL DATA [58].

\begin{tabular}{|c|c|c|c|}
\hline \multicolumn{2}{|c|}{ Model parameters } & RTC & PWP \\
\hline \multirow{3}{*}{ El Tayyan } & $C_{1}$ & $7.6053 \cdot 10^{-01}$ & 1.03317 \\
\cline { 2 - 4 } & $C_{2}$ & $5.5678 \cdot 10^{-02}$ & 2.4751 \\
\cline { 2 - 4 } & RMSE [A] & $1.029 \cdot 10^{-02}$ & $4.092 \cdot 10^{-02}$ \\
\hline \multirow{2}{*}{$\begin{array}{c}\text { Karmalkar \& } \\
\text { Haneefa }\end{array}$} & $\gamma$ & $9.9322 \cdot 10^{-01}$ & 1.0422 \\
\cline { 2 - 4 } & $m$ & $1.0014 \cdot 10^{+01}$ & 6.9996 \\
\cline { 2 - 4 } & RMSE [A] & $8.159 \cdot 10^{-03}$ & $1.649 \cdot 10^{-02}$ \\
\hline Das & $k$ & $1.0021 \cdot 10^{+01}$ & 6.9669 \\
\cline { 2 - 4 } & $h$ & $4.2531 \cdot 10^{-03}$ & $-3.822 \cdot 10^{-02}$ \\
\cline { 2 - 4 } & RMSE $[\mathrm{A}]$ & $8.656 \cdot 10^{-03}$ & $1.556 \cdot 10^{-02}$ \\
\hline
\end{tabular}

the proposed approach is less precise than the numerical one proposed by Easwarakhanthan et al. (1986), showing a larger RMSE. Nevertheless, it can also be underlined that this larger error in the proposed approach can be reduced by optimizing the initial value of the ideality factor $a$ by an iterative process.

The results from the explicit models (El Tayyan, Karmalkar and Haneefa, and Das) applied to both the RTC France solar cell and the Photowatt PWP 201 solar panel, and solved with the proposed equations for the Lambert $\mathrm{W}$-function, are included in Figs. 9 and 10. A relevant match with the testing results can be observed (with the exception of the fitting of El Tayyan's method to the PWP 201 experimental data), with reasonably reduced values of RMSE (see Table IV). The current error $\Delta I$ in relation to the testing results, is plotted in the bottom graphs of Figs. 9 and 10 . As shown by the 1-D/2-R equivalent circuit model, the maximum errors in relation to $I_{\mathrm{mp}}$ are not large: $0.62 \%$ (RTC) and $3.5 \%$ (PWP 201) for output voltages lower than $V_{\mathrm{mp}}$, and $3.2 \%$ (RTC) and $2.1 \%$ (PWP 201) for output voltages larger than $V_{\mathrm{mp}}$. These results exclude those from El-Tayyan's model, whose maximum errors are approximately twice those from the other two explicit models. This poorer performance of El Tayyan's method has already been suggested [39].

Finally, it should be emphasized that the fairly accurate results obtained with the proposed methodology (i.e., the use of the Lambert W-Function when solving the 1-D/2-R equivalent circuit model and the explicit methods), are obtained by very simple calculations (in contrast with numerical methodologies) to solve the aforementioned models. This is the most important merit of the present article. 


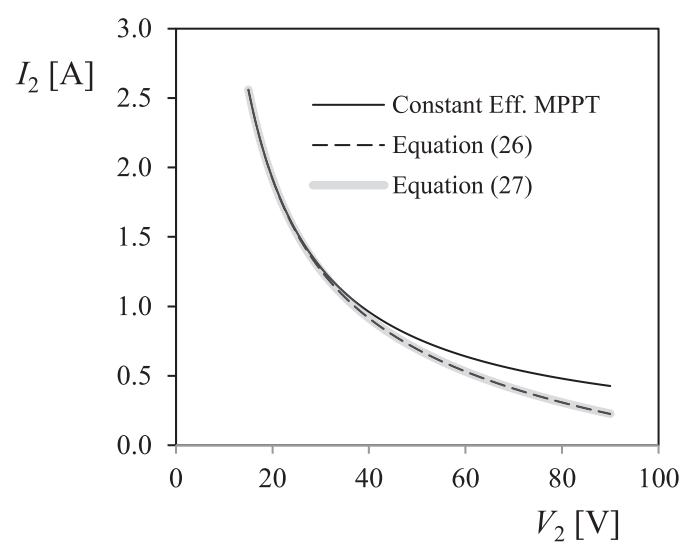

Fig. 11. Output current, $I_{2}$, from a MPPT system with the following characteristics: $V_{1}=\mathrm{V}, I_{1}=\mathrm{A}, \eta_{\max }=0.8$, and $I_{\mathrm{ch}}=0.3 \mathrm{~A}$ [see (24) to (28)], in relation to the output voltage $V_{2}$. The current, calculated by (26) and (27) is compared to the resulting one from a constant efficiency MPPT whose value is equal to $\eta_{\max }(24)$

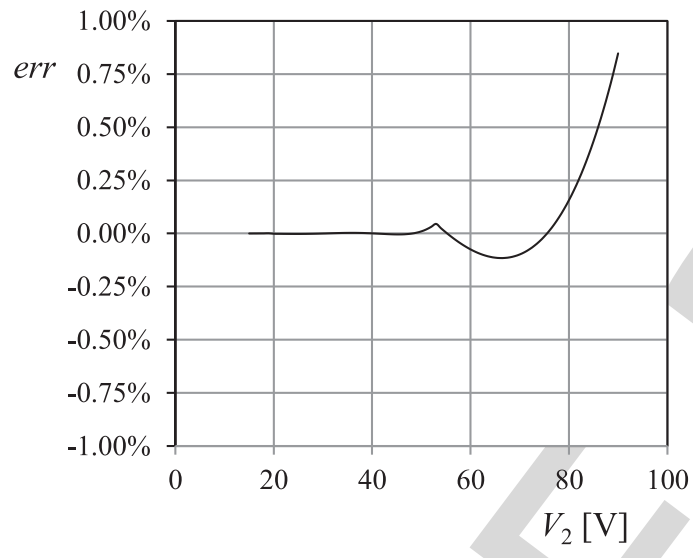

Fig. 12. Percentage error [err, see (39)] of the output current $I_{2}$ calculated by (27) [and the proposed approach to the left side of the Lambert W-function positive branch, (36) to (38)], with regard to the current calculated by solving (26). The error, err, is plotted in relation to the output yoltage $V_{2}$. (See also Fig. 11.)
Fig. 12 shows that the error related to equation (27), solved with the suggested approach to the Lambert $\mathrm{W}$-function defined by (36) to (38), is lower than $1 \%$.

\section{CONCLUSION}

The Lambert W-function has revealed itself to be a relevant tool for solving the implicit equations that arise when analyzing photovoltaic systems performance. However, working with this mathematical function can be a challenge as it is not represented by any direct equation.

In the present article, simple equations are successfully derived for the Lambert W-function in the following cases.

1) Direct calculation of the photovoltaic output current $I$ as a function of the output voltage $V$ by using the 1diode/2-resistor equivalent circuit model (with all the five parameters being well defined).

2) Calculation of the series resistor parameter $R_{s}$ from the 1-diode/2-resistor equivalent circuit model in relation to the characteristic points of the $I-V$ curve $\left(I_{\mathrm{sc}}, I_{\mathrm{mp}}, V_{\mathrm{oc}}\right.$, and $V_{\mathrm{mp}}$ ), the ideality factor $a$ the number of the seriesconnected cells of the photovoltaic device, and the thermal voltage $V_{T}$.

3) Calculation of the parameters from the explicit methods by El Tayyan, Karmalkar and Hannefa, and Das.

4) Calculation of the output current of a photovoltaic system composed of a solar panel and an MPPT based on a dc$\mathrm{dc}$ converter, when the efficiency of this maximum peak power tracking is modeled by a simple first-order system equation.

The proposed Lambert $\mathrm{W}$-function equations were checked with well-known standard information from the RTC solar cell and the Photowatt PWP 201 solar panel $[I-V$ curves from Easwarakhanthan et al. (1986)]. The results obtained from fitting the 1-D/2-R equivalent circuit model (with an initial condition $a=1$ ) indicate a $4.6 \%$ maximum error (in relation to $I_{\mathrm{mp}}$ ). This is quite a relevant result, bearing in mind that this accuracy can be improved by optimizing the ideality factor $a$, and how easily it was obtained by using the proposed equations for the Lambert W-function. Additionally, the fitting of three explicit models to the aforementioned testing data was carried out with the derived equations. The results from the Karmalkar and Haneefa and Das models indicate a $3.5 \%$ maximum error (in relation to $I_{\mathrm{mp}}$ ). The results related to El Tayyan's model are less accurate, the lack of accuracy being related to the model itself.

The results regarding the Lambert $\mathrm{W}$-function equations when analyzing MPPT behavior, were also checked by a direct comparison with the numerical solution. The results obtained by the use of the procedure described in the present article have a maximum difference of $1 \%$ in relation to the numerical solution.

\section{APPENDIX}

Analytical approximation to the Lambert W-function proposed by Barry et al. [22]

$$
W_{0}^{-}(x)=-1+\frac{\sqrt{\varphi}}{1+\left(\left(N_{1} \sqrt{\varphi}\right) / N_{2}+\sqrt{\varphi}\right)}
$$

$$
\text { err }=\frac{I_{2, \text { eq.(27) }}-I_{2, \text { eq.(26) }}}{I_{2, \text { eq.(26) }}} \text {. }
$$


437 where

$$
\begin{aligned}
& \varphi=2(1+e x) \\
& N_{1}=\left(1-\frac{1}{\sqrt{2}}\right)\left(N_{2}+\sqrt{2}\right) \\
& N_{2}=3 \sqrt{2}+6-\frac{(2237+1457 \sqrt{2}) e-4108 \sqrt{2}-5764}{(215+199 \sqrt{2}) e-430 \sqrt{2}-796} \varphi \\
& W_{0}^{+}(x)=1.4586887 \ln \left(\frac{1.2 x}{\ln (2.4 x / \ln (1+2.4 x))}\right) \\
& -0.4586887 \ln \left(\frac{2 x}{\ln (1+2 x)}\right) \\
& W_{-1}(x)=-1-\sigma-5.95061\left(1-\frac{1}{1+f(\sigma)}\right)
\end{aligned}
$$

[11] E. Roibás-Millán, F. Sorribes-Palmer, M. Chimeno-Manguán, J. Cubas, and S. Pindado, "The Spanish contribution to the 1st ESA academy's concurrent engineering challenge: Design of the moon explorer and observer of water-ice (MEOW) mission," in Proc. 8th Int. Workshop Syst. Concurrent Eng. Space Appl., 2018.

[12] J. Cubas, A. M. Gomez-Sanjuan, and S. Pindado, "On the thermo-electric modelling of smallsats," in Proc. 50th Int. Conf. Environ. Syst., 2020, pp. $1-12$.

[13] F. J. Garcia-Sanchez, "On the convenience of teaching the lambert w function in science and engineering education curricula," researchgate," 2019. [Online]. Available: https://www.researchgate.net/publication/ 336666853 On the Convenience of Teaching the Lambert W Function_in_Science_and_Engineering_Education_Curricula

[14] F. Ghani, M. Duke, and J. Carson, "Numerical calculation of series and shunt resistances and diode quality factor of a photovoltaic cell using the Lambert W-function,” Sol. Energy, vol. 91, pp. 422-431, 2013.

[15] S. xian Lun, S. Wang, G. hong Yang, and T. ting Guo, "A new explici double-diode modeling method based on Lambert W-function for photovoltaic arrays," Sol. Energy, vol. 116, pp. 69-82, 2015.

[16] X. Gao, Y. Cui, J. Hu, G. Xu, and Y. Yu, "Lambert W-function based exact representation for double diode model of solar cells: Comparison on fitness and parameter extraction," Energy Convers. Manag., vol. 127 pp. 443-460, 2016.

[17] J. Polo et al., "Modeling I-V curves of photovoltaic modules at indoor and outdoor conditions by using the Lambert function," Energy Convers. Manag., vol. 195, pp. 1004-1011, 2019.

[18] M. Calasan, S. H. E. Abdel Aleem, and A. F. Zobaa, "On the root mean square error (RMSE) calculation for parameter estimation of photovoltaic models: A novel exact analytical solution based on lambert W function,' Energy Convers. Manag., vol. 210, 2020.

[19] H. M. Ridha, "Parameters extraction of single and double diodes photovoltaic models using marine predators algorithm and Lambert w function,' Sol. Energy, vol. 209, pp. 674-693, 2020.

[20] D. Sarkar, A. Kumar, and P. K. Sadhu, "Different diode models comparison using lambert $\mathrm{w}$ function for extracting maximum power from BIPV modules," Int. J. Energy Res., pp. 1-12, 2020.

We are indebted to the Director of the IDR/UPM Institute, Prof. Angel Sanz-Andres, for his constant support in relation to all research activities carried out in this institution. We are indebted to Anna Maria Ballester-Bohn for her kind help in improving the text style. We are also grateful to the Reviewers, whose comments helped to improve this article.

\section{REFERENCES}

[1] L. Hernández-Callejo, S. Gallardo-Saavedra, and V. Alonso-Gómez, “A review of photovoltaic systems: Design, operation and maintenance," Sol. Energy, vol. 188, no. June, pp. 426-440, 2019.

[2] P. G. V. Sampaio and M. O. A. González, "Photovoltaic solar energy: Conceptual framework," Renew. Sustain. Energy Rev., vol. 74, pp. 590-601, Jul. 2017.

[3] M. H. Shubbak, "Advances in solar photovoltaics: Technology review and patent trends," Renew. Sustain. Energy Rev., vol. 115, 2019, Art. no. 109383.

[4] A. S. Sarkın, N. Ekren, and Ş. Sağlam, "A review of anti-reflection and self-cleaning coatings on photovoltaic panels," Sol. Energy, vol. 199, pp. 63-73, 2020.

[5] V. Muteri et al., "Review on life cycle assessment of solar photovoltaic panels," Energies, vol. 13, no. 1, 2020.

[6] M. Krebs-Moberg, M. Pitz, T. L. Dorsette, and S. H. Gheewala, "Third generation of photovoltaic panels: A life cycle assessment," Renew. Energy, vol. 164, pp. 556-565, 2021.

[7] A. M. Humada et al., "Modeling of PV system and parameter extraction based on experimental data: Review and investigation," Sol. Energy, vol. 199, pp. 742-760, 2020

[8] E. Roibás-Millán et al., "Implementation of concurrent engineering approach in MUSE (Master in space systems) master's degree in space engineering," in Proc. Athens, ATINER'S Conf. Paper Ser., 2018, pp. 1-19.

[9] J. B. Ballesteros, J. M. Alvarez, P. Arcenillas, E. Roibas, J. Cubas, and S. Pindado, "CDF as a tool for space engineering master's student collaboration and concurrent design learning," in Proc. 8th Int. Workshop Syst. Concurrent Eng. Space Appl., 2018.

[10] E. Roibás-Millán, F. Sorribes-Palmer, and M. Chimeno-Manguán, “The MEOW lunar project for education and science based on concurrent engineering approach," Acta Astronaut, vol. 148, pp. 111-120, Jul. 2018.
[21] D. Yousri, M. Abd Elaziz, D. Oliva, L. Abualigah, M. A. A. Al-qaness, and A. A. Ewees, "Reliable applied objective for identifying simple and detailed photovoltaic models using modern metaheuristics: Comparative study," Energy Convers. Manag., vol. 223, 2020.

[22] D. A. Barry, J. Y. Parlange, L. Li, H. Prommer, C. J. Cunningham, and F. Stagnitti, "Analytical approximations for real values of the Lambert W-function," Math. Comput. Simul., vol. 53, no. 1/2, pp. 95-103, 2000.

[23] J. Cubas, S. Pindado, and M. Victoria, "On the analytical approach for modeling photovoltaic systems behavior," J. Power Sources, vol. 247 pp. 467-474, Feb. 2014.

[24] D. T. Cotfas, P. A. Cotfas, and S. Kaplanis, "Methods to determine the dc parameters of solar cells: A critical review," Renew. Sustain. Energy Rev. vol. 28, pp. 588-596, 2013.

[25] A. K. Tossa, Y. M. Soro, Y. Azoumah, and D. Yamegueu, “A new approach to estimate the performance and energy productivity of photovoltaic modules in real operating conditions," Sol. Energy, vol. 110, pp. 543-560, 2014.

[26] A. Ortiz-Conde, F. J. García-Sánchez, J. Muci, and A. Sucre-González, "A review of diode and solar cell equivalent circuit model lumped parameter extraction," FACTA Univ. Ser. Electron. Energ., vol. 27, pp. 57-102, 2014.

[27] D. Jena and V. V. Ramana, "Modeling of photovoltaic system for uniform and non-uniform irradiance: A critical review," Renew. Sustain. Energy Rev., vol. 52, pp. 400-417, 2015.

[28] V. J. Chin, Z. Salam, and K. Ishaque, "Cell modelling and model pareview," Appl. Energy, vol. 154, pp. 500-519, 2015.

[29] A. M. Humada, M. Hojabri, S. Mekhilef, and H. M. Hamada, "Solar cell parameters extraction based on single and double-diode models: A review,' Renew. Sustain. Energy Rev., vol. 56, pp. 494-509, 2016.

[30] H. Ibrahim and N. Anani, "Evaluation of analytical methods for parameter extraction of PV modules," Energy Procedia, vol. 134, pp. 69-78, 2017.

[31] E. Roibás-Millán et al., "Lambert W-function simplified expressions for photovoltaic current-voltage modelling," in Proc. 20th IEEE Int. Conf. Environ. Elect. Eng., 2020, pp. 1630-1635.

[32] E. Roibás-Millán, D. Alfonso-Corcuera, J. Cubas, J. M. Alvarez, S. Pindado, and A. M. Gomez-Sanjuan, "Performance analysis of photovoltaic systems: Research at IDR/UPM institute," in Proc. 20th IEEE Int. Conf. Environ. Elect. Eng., 2020, pp. 769-774. rameters estimation techniques for photovoltaic simulator application: A 
[33] J. Cubas, S. Pindado, and A. Farrahi, "New method for analytical photovoltaic parameter extraction," in Proc. 2nd Int. Conf. Renew. Energy Res. Appl., 2013, pp. 873-877.

[34] M. G. Villalva, J. R. Gazoli, and E. R. Filho, "Modeling and circuit-based simulation of photovoltaic arrays," in Proc. Braz. Power Electron. Conf., 2009, pp. 1244-1254.

[35] M. G. Villalva, J. R. Gazoli, and E. R. Filho, "Comprehensive approach to modeling and simulation of photovoltaic arrays," IEEE Trans. Power Electron., vol. 24, no. 5, pp. 1198-1208, May 2009.

[36] L. Peng, Y. Sun, Z. Meng, Y. Wang, and Y. Xu, "A new method for determining the characteristics of solar cells," J. Power Sources, vol. 227, pp. 131-136, Apr. 2013

[37] J. Cubas, S. Pindado, and C. de Manuel, "Explicit expressions for solar panel equivalent circuit parameters based on analytical formulation and the Lambert W-Function," Energies, vol. 7, no. 7, pp. 4098-4115, Jun. 2014.

[38] S. Pindado and J. Cubas, "Simple mathematical approach to solar cell/panel behavior based on datasheet information," Renew. Energy, vol. 103, pp. 729-738, 2017.

[39] S. Pindado, J. Cubas, E. Roibás-Millán, F. Bugallo-Siegel, and F. SorribesPalmer, "Assessment of explicit models for different photovoltaic technologies," Energies, vol. 11, no. 6, 2018, Art. no. 1353.

[40] M. Oulcaid, H. E. Fadil, L. Ammeh, A. Yahya, and F. Giri, "One shape parameter-based explicit model for photovoltaic cell and panel,' Sustain. Energy, Grids Netw., vol. 21, 2020, Art. no. 100312.

[41] J. Cubas, S. Pindado, and Á. Sanz-Andrés, "Accurate simulation of MPPT methods performance when applied to commercial photovoltaic panels," Sci. World J., vol. 2015, 2015, Art. no. 914212.

[42] M. Veerachary, T. Senjyu, and K. Uezato, "Voltage-based maximum power point tracking control of PV system," IEEE Trans. Aerosp. Electron. Syst., vol. 38, no. 1, pp. 262-270, Jan. 2002.

[43] R. Leyva, C. Alonso, I. Queinnec, A. Cid-Pastor, D. Lagrange, and L. Martínez-Salamero, "MPPT of photovoltaic systems using extremum Seeking control," IEEE Trans. Aerosp. Electron. Syst., vol. 42, no. 1, pp. 249-258, Jan. 2006.

[44] H. Dehbonei, S. R. Lee, and H. Nehrir, "Direct energy transfer for high efficiency photovoltaic energy systems part I: Concepts and hypothesis,' IEEE Trans. Aerosp. Electron. Syst., vol. 45, no. 1, pp. 31-45, Jan. 2009.

[45] M. Miyatake, M. Veerachary, F. Toriumi, N. Fujii, and H. Ko, "Maximum power point tracking of multiple photovoltaic arrays: A PSO approach,' IEEE Trans. Aerosp. Electron. Syst., vol. 47, no. 1, pp. 367-380, Jan. 2011

[46] M. B. Shadmand, M. Mosa, R. S. Balog, and H. A. Rub, "An improved MPPT technique for high gain DC-DC converter using model predictive control for photovoltaic applications," in Proc. IEEE Appl. Power Electron. Conf. Expo., 2014, pp. 2993-2999.

[47] S. Li, H. Liao, H. Yuan, Q. Ai, and K. Chen, "A MPPT strategy with variable weather parameters through analyzing the effect of the DC/DC converter to the MPP of PV system,' Sol. Energy, vol. 144, pp. 175-184, 2017.

[48] S. Öztürk, P. Poşpoş, V. Utalay, A. Koç, M. Ermiş, and I. Çadırcı, "Operating principles and practical design aspects of all SiC DC/AC/DC converter for MPPT in grid-connected PV supplies," Sol. Energy, vol. 176, pp. 380-394, Dec. 2018.

[49] A. Raj, S. R. Arya, and J. Gupta, "Solar PV array-based DC-DC converter with MPPT for low power applications," Renew. Energy Focus, vol. 34 no. 00, pp. 109-119, 2020.

[50] E. Koutroulis and F. Blaabjerg, "Overview of maximum power point tracking techniques for photovoltaic energy production systems," Elect. Power Compon. Syst., vol. 43, no. 12, pp. 1329-1351, 2015.

[51] S. Lyden and M. E. Haque, "Maximum power point tracking techniques for photovoltaic systems: A comprehensive review and comparative analysis," Renew. Sustain. Energy Rev., vol. 52, pp. 1504-1518, 2015.
[52] L. Liu, X. Meng, and C. Liu, "A review of maximum power point tracking methods of PV power system at uniform and partial shading," Renew. Sustain. Energy Rev., vol. 53, pp. 1500-1507, 2016.

[53] D. Verma, S. Nema, A. M. Shandilya, and S. K. Dash, "Maximum power point tracking (MPPT) techniques: Recapitulation in solar photovoltaic systems," Renew. Sustain. Energy Rev., vol. 54, pp. 1018-1034, 2016.

[54] A. K. Gupta and R. Saxena, "Review on widely-used MPPT techniques for PV applications," in Proc. 1st Int. Conf. Innov. Challenges Cyber Secur., 2016, pp. 270-273.

[55] O. Singh and S. K. Gupta, "A review on recent MPPT techniques for photovoltaic system," in Proc. IEEMA Eng. Infin. Conf., 2018

[56] M. Dhimish, "Assessing MPPT techniques on hot-spotted and partially shaded photovoltaic modules: Comprehensive review based on experimental data," IEEE Trans. Electron Devices, vol. 66, no. 3, pp. 1132-1144, Mar. 2019.

[57] I. Yadav, S. K. Maurya, and G. K. Gupta, "A literature review on industrially accepted MPPT techniques for solar PV system," Int. J. Elect. Comput. Eng., vol. 10, no. 2, pp. 2117-2127, 2020.

[58] T. Easwarakhanthan, J. Bottin, I. Bouhouch, and C. Boutrit, "Nonlinear minimization algorithm for determining the solar cell parameters with microcomputers," Int. J. Sol. Energy, vol. 4, no. 1, pp. 1-12, Jan. 1986.

[59] R. Chenouard and R. A. El-Sehiemy, "An interval branch and bound global optimization algorithm for parameter estimation of three photovoltaic models," Energy Convers. Manag., vol. 205, 2020, Art. no. 112400.

[60] A. A. Z. DIab, H. M. Sultan, T. D. Do, O. M. Kamel, and M. A. Mossa, "Coyote optimization algorithm for parameters estimation of various models of solar cells and PV modules," IEEE Access, vol. 8, pp. 111102-111140, 2020 .

[61] Q. Hao, Z. Zhou, Z. Wei, and G. Chen, "Parameters identification of photovoltaic models using a multi-strategy success-history-based adaptive differential evolution," IEEE Access, vol. 8, pp. 35979-35994, 2020.

[62] S. Li, Q. Gu, W. Gong, and B. Ning, "An enhanced adaptive differential evolution algorithm for parameter extraction of photovoltaic models," Energy Convers. Manag., vol. 205, 2020, Art. no. 112443.

[63] J. Liang et al., "Classified perturbation mutation based particle swarm optimization algorithm for parameters extraction of photovoltaic models,' Energy Convers. Manag., vol. 203, 2020, Art. no. 112138.

[64] J. Liang et al., "Parameters estimation of solar photovoltaic models via a self-adaptive ensemble-based differential evolution," Sol. Energy, vol. 207, no. C, pp. 336-346, 2020.

[65] X. Lin and Y. Wu, "Parameters identification of photovoltaic models using niche-based particle swarm optimization in parallel computing architecture," Energy, vol. 196, 2020, Art. no. 117054

[66] W. Long, S. Cai, J. Jiao, M. Xu, and T. Wu, "A new hybrid algorithm based on grey wolf optimizer and cuckoo search for parameter extraction of solar photovoltaic models," Energy Convers. Manag., vol. 203, 2020, Art. no. 112243

[67] R. Ben Messaoud, "Extraction of uncertain parameters of single and double diode model of a photovoltaic panel using salp swarm algorithm," Meas. J. Int. Meas. Confed., vol. 154, 2020, Art. no. 107446.

[68] G. Xiong, J. Zhang, D. Shi, L. Zhu, X. Yuan, and Z. Tan, "Winner-leading competitive swarm optimizer with dynamic Gaussian mutation for parameter extraction of solar photovoltaic models," Energy Convers. Manag. vol. 206, 2020, Art. no. 112450

[69] D. Yousri, S. B. Thanikanti, D. Allam, V. K. Ramachandaramurthy, and M. B. Eteiba, "Fractional chaotic ensemble particle swarm optimizer for identifying the single, double, and three diode photovoltaic models' parameters," Energy, vol. 195, 2020, Art. no. 116979.

[70] K. Bouzidi, M. Chegaar, and A. Bouhemadou, "Solar cells parameters evaluation considering the series and shunt resistance," Sol. Energy Mater. Sol. Cells, vol. 91, no. 18, pp. 1647-1651, Nov. 2007. 


\section{GENERAL INSTRUCTIONS}

- Authors: Carefully check the page proofs (and coordinate with all authors); additional changes or updates WILL NOT be accepted after the article is published online/print in its final form. Please check author names and affiliations, funding, as well as the overall article for any errors prior to sending in your author proof corrections.

- Authors: Please check ALL author names for correct spelling, abbreviations, and order of first and last name in the byline, affiliation footnote, and bios.

- Authors: We cannot accept new source files as corrections for your article. If possible, please annotate the PDF proof we have sent you with your corrections and upload it via the Author Gateway. Alternatively, you may send us your corrections in list format. You may also upload revised graphics via the Author Gateway.

- Authors: Please note that once you upload your changes, they will be entered and your article finalized. The proofing process is now complete and your article will be sent for final publication and printing. If you would like an additional proof to review, this should be noted as it is not IEEE policy to send multiple proofs. Once your article is posted on Xplore, it is considered final and the article of record. No further changes will be allowed at this point so please ensure scrutiny of your final proof.

- Authors: Unless invited or otherwise informed, a mandatory Excessive Article Length charges will be incurred if your article is over the page limit set by the society in the Information for Authors.

\section{QUERIES}

Q1. Author: Please check and confirm whether the name of the authors in the byline are correct as set.

Q2. Author: Please confirm or add details for any funding or financial support for the research of this article.

Q3. Author: Please check the sentence "The left side... evaluated at" for correctness.

Q4. Author: Please provide the page range in Refs. [5], [9], [11], [18], [21], and [55]

Q5. Author: Please provide the volume number in Ref. [20]. 


\title{
Simplified Lambert W-Function Math Equations When Applied to Photovoltaic Systems Modeling
}

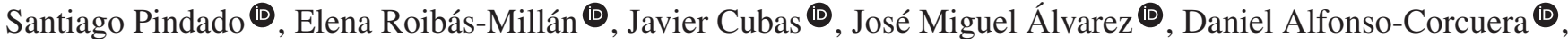

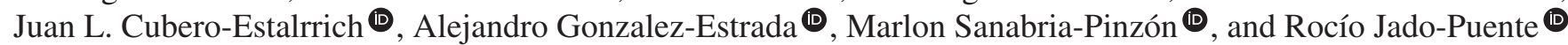

\begin{abstract}
In this article, simplified and easy-to-work-with equations for the Lambert W-function are derived. This function is widely used to solve equations related to photovoltaic systems. More specifically, this mathematical function represents a useful tool when modeling solar cells/panels performance (that is, the currentvoltage curve) by analytical approaches. However, the Lambert W-function has a complex solving process which might represent an unaffordable mathematical challenge for a great number of professionals/technicians in the photovoltaic industrial sector. Simple approximations for the Lambert W-function on both of its branches (positive and negative) are proposed in this article. The results of the present article show a simple but accurate way for photovoltaic systems modeling, even when these systems comprise a maximum power point tracking subsystem.
\end{abstract}

Index Terms-1-diode/2-resistor model, I-V curve, Lambert Wfunction, maximum power point tracking (MPPT), photovoltaic systems performance, solar cell, solar panel.

\section{INTRODUCTION}

$\mathbf{R}$ ENEWABLE energy plays a very important role in reducing fossil resources consumption [1], which is a present and urgent need for mankind due to problems, such as global warming, climate change and air pollution [2]. Among the different renewable energy sources, solar energy is probably the most relevant, as it is clean, safe, and unlimited [3], [4].

The figures can be overwhelming. In one year the amount of energy received from the sun is 10000 times larger than the world's energy consumption [4]. The installed photovoltaic power increased from $100.9 \mathrm{GW}$ in 2012 to $230 \mathrm{GW}$ in 2015 , reaching $400 \mathrm{GW}$ in 2017 [1], [5]. This rate of increase has been

Manuscript received September 13, 2020; revised October 16, 2020 and December 7, 2020; accepted January 6, 2021. Paper 2020-SECSC-1403.R2, presented at the 2020 IEEE International Conference on Environment and Electrical Engineering and 2020 IEEE Industrial and Commercial Power Systems Europe, Madrid, Spain, Jun. 9-12, and approved for publication in the IEEE TRANSACTIONS ON INDUSTRY APPLICATIONS by the Renewable and Sustainable Energy Conversion Systems Committee of the IEEE Industry Applications Society. (Corresponding author: Santiago Pindado.)

The authors are with the Instituto de Microgravedad "Ignacio Da Riva" (IDR/UPM) Escuela Técnica Superior de Ingeniería Aeronáutica y del Espacio (ETSIAE), Universidad Politécnica de Madrid, 28040 Madrid, Spain (e-mail: santiago.pindado@upm.es; elena.roibas@upm.es; j.cubas@upm.es; jm.alvarez@upm.es; daniel.alfonso.corcuera@alumnos.upm.es; jl.cubero@ alumnos.upm.es; alejandro.gonzalez.estrada@alumnos.upm.es; ms.sanabria@ alumnos.upm.es; rocio.jado.puente@alumnos.upm.es).

Color versions of one or more of the figures in this article are available at https://doi.org/10.1109/TIA.2021.3052858.

Digital Object Identifier 10.1109/TIA.2021.3052858 possible due to a new generation of solar cells that allow production growth while reducing costs and environmental impact [6].

Modeling has become the key for photovoltaic system design and development, as it allows proper and accurate energy production forecasts [7]. The modeling of these photovoltaic systems (solar cells or solar panels) is normally carried out by using equivalent circuit models, whose equations are quite challenging as they are mathematically implicit expressions. Nevertheless, in the last decade the Lambert W-function has been revealed as a powerful tool to solve these equations.

The aim of the present article is to derive simple expressions for the Lambert W-function, which is commonly used in photovoltaic systems, and describe how this function is required to solve equations related to these systems. The proposed expressions were derived by fitting well-known mathematical equations (polynomials, exponential functions, hyperbolic functions) to points on the Lambert $\mathrm{W}$-function calculated numerically with the highest available accuracy. The work carried out in the IDR/UPM Institute has prompted the authors to carry out the present article, as simple solutions to analyze solar panel behavior are required when developing spacecraft missions in a concurrent design facility [[8]-[11]], or analyzing thermoelectric coupled behavior [12].

The innovation offered by the present article is to derive very simple expressions for the Lambert W-function that can be solved quickly with a pocket calculator, to model a photovoltaic systems performance (or that can be easily programmed for complex simulations, such as the thermo-electric analysis of space systems).

The rest of this article is organized as follows. In Section II, the Lambert W-Function is described in relation to its use in photovoltaic systems modeling. In Section III, the different mathematical expressions derived to estimate the Lambert Wfunction branches $W_{-1}, W_{0}{ }^{+}$, and $W_{0}{ }^{-}$, are defined, together with their accuracy. In Section IV, the results of the use of these equations are shown. Finally, the conclusions is summarized in Section V.

\section{LAMBERT W-FUNCTION}

The Lambert W-function has proven to be a very useful tool for solving equations related to: time-delay differential problems, control stability, flight dynamics of projectiles, enzyme kinetics, and solid-state electronics modeling problems 


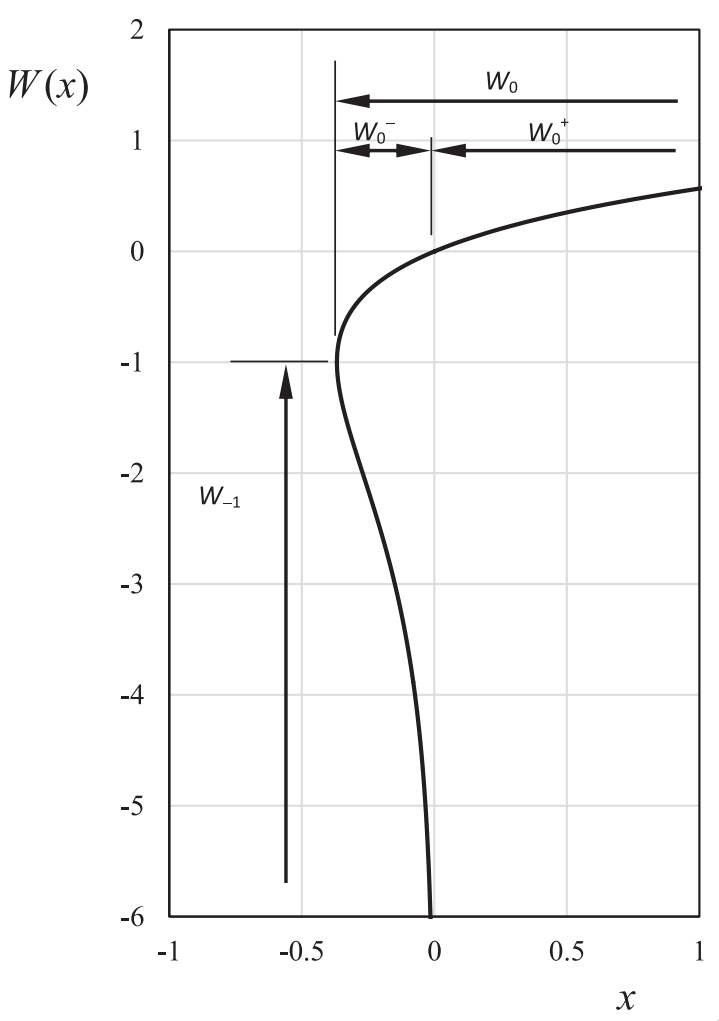

Fig. 1. Lambert W-function. The different branches are indicated in the graph.

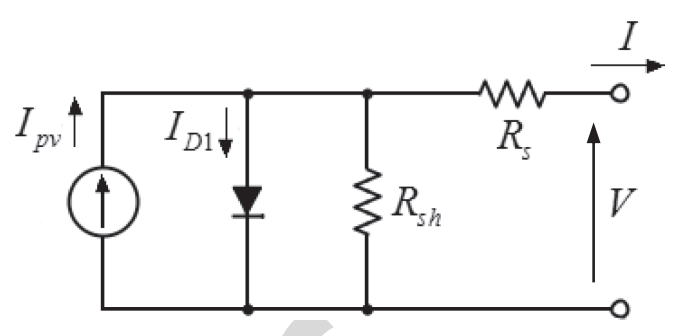

Fig. 2. Solar cell/panel 1-diode/2-resistor equivalent circuit.

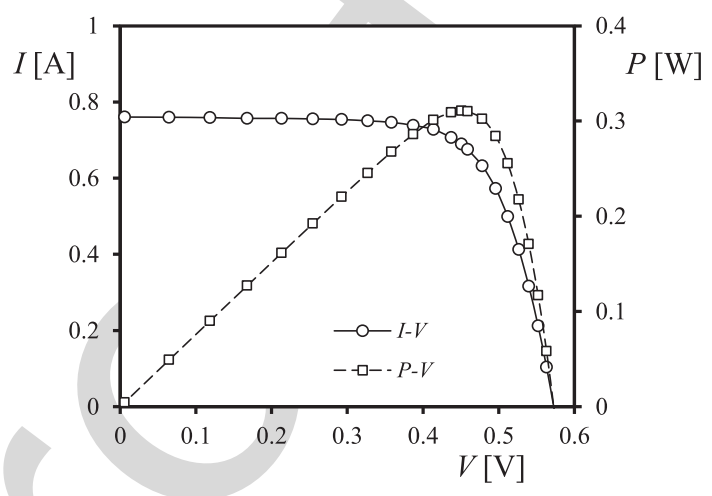

Fig. 3. $\quad I-V$ (current-voltage) and $P-V$ (power-voltage) curves of a Si solar cell.

model (see Fig. 2) is the following [23]:

$$
I=I_{p v}-I_{0}\left[\exp \left(\frac{V+I R_{s}}{n a V_{T}}\right)-1\right]-\frac{V+I R_{s}}{R_{s h}}
$$

in which the first term is the photocurrent, the second term is the current through the diode, and the third term represents the current through the shunt resistor. $V_{T}$ is the thermal voltage ( $V_{T}=\kappa T / q ; \kappa$ being the Boltzmann constant, $T$ the temperature, and $q$ the electron charge), $a$ is the ideality factor of the diode and $n$ is the number of series-connected cells within the panel.

Working with the above equation is not a simple task, as the parameters involved in the equation $\left(I_{p v}, I_{0}, a, R_{s}\right.$, and $\left.R_{s h}\right)$ should be calculated to fit the equation to a specific $I-V$ curve (see Fig. 3), which depends on both the solar irradiance, $G$, on the cell/panel and its temperature, $T$.

Equation (1) is an implicit mathematical expression. Therefore, for a given value of the output voltage $V$ the calculation of the corresponding output current $I$ is not immediate, which makes an iteration process necessary. Nevertheless, different methodologies have been developed to work with this equation depending on the available information [24]-[30].

Among the aforementioned methodologies developed to fit equation (1) to a specific $I-V$ curve, it is possible to mention numerical and analytical ones. Numerical techniques fit the equation by using different algorithms. These procedures obtain very accurate results. However, they require both high computational resources and skill. Additionally, they might be a drawback if coupled calculations are required (thermoelectric calculations of the behavior of solar panels in space are a good example of this sort of calculation [12]). 
On the other hand, analytical procedures are simpler and based on limited information from the $I-V$ curve, its characteristic points are as follows [31], [32]:

1) short circuit current $I_{\mathrm{SC}}$;

2) open circuit voltage $V_{\text {oc }}$;

3) current and voltage at maximum power point (MPP) $I_{\mathrm{mp}}$ and $V_{\mathrm{mp}}$.

Analytical methodologies are not as accurate as the numerical ones, but can offer quick and satisfactory results.

If the characteristic points of the $I-V$ curve are known for certain values of sun irradiance $G$ and the temperature $T$, it is possible to calculate four of the parameters of the model in relation to the fifth one, which is the ideality factor, $a$ [23], [33]

$$
\begin{aligned}
I_{p v}= & \frac{R_{s h}+R_{s}}{R_{s h}} I_{\mathrm{sc}} \\
I_{0}= & \frac{\left(R_{s h}+R_{s}\right) I_{\mathrm{sc}}-V_{\mathrm{oc}}}{R_{s h} \exp \left(\frac{V_{\mathrm{oc}}}{n a V_{T}}\right)} \\
& \times \frac{n a V_{T} V_{\mathrm{mp}}\left(2 I_{\mathrm{mp}}-I_{\mathrm{sc}}\right)}{\left(\begin{array}{l}
\left(V_{\mathrm{mp}} I_{\mathrm{sc}}+V_{\mathrm{oc}}\left(I_{\mathrm{mp}}-I_{\mathrm{sc}}\right)\right)\left(V_{\mathrm{mp}}-I_{\mathrm{mp}} R_{s}\right) \\
-n a V_{T}\left(V_{\mathrm{mp}} I_{\mathrm{sc}}-V_{\mathrm{oc}} I_{\mathrm{mp}}\right)
\end{array}\right)} \\
= & \exp \left(\frac{V_{\mathrm{mp}}+I_{\mathrm{mp}} R_{s}-V_{\mathrm{oc}}}{n a V_{T}}\right) \\
R_{s h}= & \frac{\left(V_{\mathrm{mp}}-I_{\mathrm{mp}} R_{s}\right)\left(V_{\mathrm{mp}}-R_{s}\left(I_{\mathrm{sc}}-I_{\mathrm{mp}}\right)-n a V_{T}\right)}{\left(V_{\mathrm{mp}}-I_{\mathrm{mp}} R_{s}\right)\left(I_{\mathrm{sc}}-I_{\mathrm{mp}}\right)-n a V_{T} I_{\mathrm{mp}}}
\end{aligned}
$$

Therefore, once the ideality factor $a$, has been estimated (according to its value within the bracket [1, 1.5] [34], [35]), it is possible to sequentially obtain $R_{s}$ [from (5)], $R_{s h}$ [from (6)], $I_{0}$ [from (4)], and $I_{\mathrm{pv}}$ [from (3)]. Finally, the output current $I$ can be defined for each value of the output voltage $V$ by means of an iterative process, or the following equation [36]:

$$
\begin{aligned}
I= & \frac{R_{s h}\left(I_{\mathrm{pv}}+I_{0}\right)-V}{R_{s h}+R_{s}} \\
& -\frac{n a V_{T}}{R_{s}} W_{0}\left(\frac{R_{s h} R_{s} I_{0}}{n a V_{T}\left(R_{s h}+R_{s}\right)}\right. \\
& \left.\exp \left(\frac{R_{s h} R_{s}\left(I_{\mathrm{pv}}+I_{0}\right)+R_{s h} V}{n a V_{T}\left(R_{s h}+R_{s}\right)}\right)\right)
\end{aligned}
$$

where $W_{0}$ is the positive branch of the Lambert W-function. In fact, the right-side sub-branch $W_{0}{ }^{+}$is the one required.

Alternatively, solving equation (5) to obtain the value of $R_{s}$ requires an iterative process, this parameter can be obtained from [37]

$$
R_{s}=A\left(W_{-1}(B \exp (C))-(D+C)\right)
$$

where $W_{-1}$ is the negative branch of the Lambert W-function and

$$
\begin{aligned}
& A=\frac{n a V_{T}}{I_{\mathrm{mp}}} \\
& B=-\frac{V_{\mathrm{mp}}\left(2 I_{\mathrm{mp}}-I_{\mathrm{sc}}\right)}{V_{\mathrm{mp}} I_{\mathrm{sc}}+V_{\mathrm{oc}}\left(I_{\mathrm{mp}}-I_{\mathrm{sc}}\right)}
\end{aligned}
$$

$$
\begin{aligned}
C & =-\frac{2 V_{\mathrm{mp}}-V_{\mathrm{oc}}}{n a V_{T}}+\frac{V_{\mathrm{mp}} I_{\mathrm{sc}}-V_{\mathrm{oc}} I_{\mathrm{mp}}}{V_{\mathrm{mp}} I_{\mathrm{sc}}+V_{\mathrm{oc}}\left(I_{\mathrm{mp}}-I_{\mathrm{sc}}\right)} \\
D & =\frac{V_{\mathrm{mp}}-V_{\mathrm{oc}}}{n a V_{T}}
\end{aligned}
$$

\section{B. Explicit Models Solved With the Lambert W-Function}

There are several explicit models to analyze the currentvoltage performance of a solar cell/panel [38], [39]. Although these approximations do not preserve any physical aspect of the photovoltaic conversion process, they are interesting and accurate enough to generate new works from time to time [40]. Among the explicit models, the ones that reach a solution based on the Lambert W-function are as follows.

1) El-Tayyan's model

$$
I=I_{s c}-C_{1} \exp \left(-\frac{V_{\mathrm{oc}}}{C_{2}}\right)\left(\exp \left(\frac{V}{C_{2}}\right)-1\right)
$$

where

$$
C_{1}=\frac{I_{\mathrm{sc}}}{1-\exp \left(-\frac{V_{\mathrm{oc}}}{C_{2}}\right)}
$$

and, if $V_{o c} / C_{2}>>1$

$$
C_{2}=\frac{V_{\mathrm{mp}}-V_{\mathrm{oc}}}{W_{-1}\left(\left(1-\frac{V_{\mathrm{oc}}}{V_{\mathrm{mp}}}\right)\left(\frac{I_{\mathrm{mp}}}{I_{\mathrm{sc}}}\right)\right)} .
$$

2) Karmalkar and Haneefa's model

$$
\frac{I}{I_{\mathrm{sc}}}=1-(1-\gamma)\left(\frac{V}{V_{\mathrm{oc}}}\right)-\gamma\left(\frac{V}{V_{\mathrm{oc}}}\right)^{m}
$$

where

$$
\begin{aligned}
& \gamma=\frac{2\left(\frac{I_{\mathrm{mp}}}{I_{\mathrm{sc}}}\right)-1}{(m-1)\left(\frac{V_{\mathrm{mp}}}{V_{\mathrm{oc}}}\right)^{m}} \\
& m=\frac{W_{-1}\left(-\left(\frac{V_{\mathrm{oc}}}{V_{\mathrm{mp}}}\right)^{\frac{1}{K}}\left(\frac{1}{K}\right) \ln \left(\frac{V_{\mathrm{mp}}}{V_{\mathrm{oc}}}\right)\right)}{\ln \left(\frac{V_{\mathrm{mp}}}{V_{\mathrm{oc}}}\right)}+\frac{1}{K}+1
\end{aligned}
$$

with

$$
K=\frac{1-\left(\frac{I_{\mathrm{mp}}}{I_{\mathrm{sc}}}\right)-\left(\frac{V_{\mathrm{mp}}}{V_{\mathrm{oc}}}\right)}{2\left(\frac{I_{\mathrm{mp}}}{I_{\mathrm{sc}}}\right)-1} .
$$

3) Das' model

$$
\frac{I}{I_{s c}}=\frac{1-\left(\frac{V}{V_{\mathrm{oc}}}\right)^{k}}{1+h\left(\frac{V}{V_{\mathrm{oc}}}\right)}
$$

where

$$
k=\frac{W_{-1}\left(\left(\frac{I_{\mathrm{mp}}}{I_{\mathrm{sc}}}\right) \ln \left(\frac{V_{\mathrm{mp}}}{V_{\mathrm{oc}}}\right)\right)}{\ln \left(\frac{V_{\mathrm{mp}}}{V_{\mathrm{oc}}}\right)}
$$




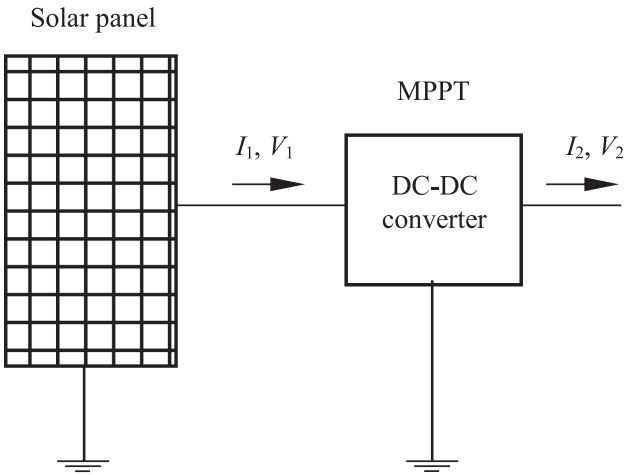

Fig. 4. Sketch of a solar panel connected to a dc-dc converter that works as MPPT.

$$
h=\left(\frac{V_{\mathrm{oc}}}{V_{\mathrm{mp}}}\right)\left(\frac{I_{\mathrm{sc}}}{I_{\mathrm{mp}}}-\frac{1}{k}-1\right) .
$$

\section{Modeling Maximum Power Point Tracking (MPPT) Performance With the Lambert W-Function}

The ambient conditions in which a solar panel works (temperature and solar irradiance), have a relevant effect on its performance [12], [37], [41]. This problem has led to the development of MPPT methods, in order to fix the working point of the solar panel at the MPP of the $I-V$ curve (see Fig. 3), no matter the level of the irradiance on the solar panel or the temperature of its cells.

Among the different electronic architectures on which MPPT systems are based, dc-dc converters should be mentioned [42] [45]. In this MPPT, the voltage at the primary winding (where the solar panel is connected, see Fig. 4) is changed in relation to the voltage at the secondary winding, to reach the aforementioned MPP [46]-[49]. Additionally, it should be noted that the process of setting the voltage at the primary winding of the $\mathrm{dc}-\mathrm{dc}$ converter at the MPP of a solar panel, in relation to the irradiance and temperature conditions, is not an immediate task, since there are many procedures available in [50]-[57].

The behavior of a solar panel can be defined by means of its efficiency, $\eta$, defined as the ratio between the input and the output power

$$
\eta=\frac{V_{2} I_{2}}{V_{1} I_{1}}
$$

where $V_{1}$ is the input voltage, $V_{2}$ is the output voltage, $I_{1}$ is the input current, and $I_{2}$ is the output current (all variables in relation to the MPPT, see Fig. 4).

The efficiency $\eta$ of the three dc-dc converters used in the UPMSat-2 satellite power distribution subsystem is plotted in relation to the output current $I_{2}$ in Fig. 5. These converters are as follows.

1) $\pm 15 \mathrm{~V}$ converter: It converts the bus voltage into +15 and $-15 \mathrm{~V}$ (this converter has two output voltage levels in relation to ground).

2) $+5 \mathrm{~V}$ converter: It converts $+15 \mathrm{~V}$ voltage into $+5 \mathrm{~V}$.

3) $+3.3 \mathrm{~V}$ converter: It converts $+15 \mathrm{~V}$ voltage into $+3.3 \mathrm{~V}$.

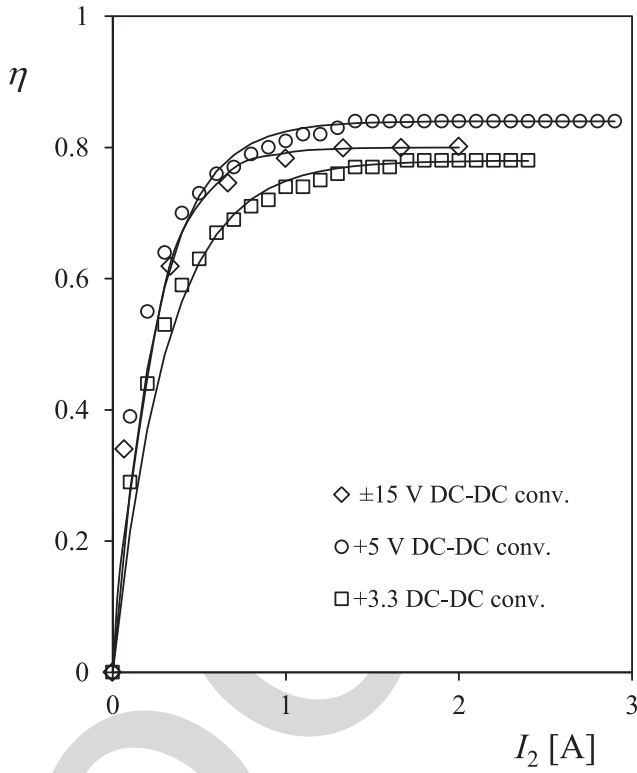

Fig. 5. Efficiency $\eta$ of the UPMSat-2 power distribution subsystem dc-dc converters in relation to the output current $I_{2}$. The fitting of (24) to the three data sets have also been plotted as solid lines.

It is possible to fit each one of these curves to the following equation:

$$
\eta=\eta_{\max }\left(1-\exp \left(g\left(I_{2}\right)\right)\right)
$$

where $\eta_{\max }$ is the maximum value of the efficiency and $f\left(I_{2}\right)$ is a function (normally, a polynomial) which depends on the output current, $I_{2}$. If the simplest approach is selected:

$$
g\left(I_{2}\right)=-\frac{I_{2}}{I_{\mathrm{ch}}} .
$$

Equation (24) becomes the well-known solution of a first order system. In the above equation, $I_{\mathrm{ch}}$ is a characteristic current.

In Fig. 5, (24) has been fitted to the three sets of data, the values of the maximum efficiency and the characteristic current being: $\eta=0.8$ and $I_{\mathrm{ch}}=0.22 \mathrm{~A}( \pm 15 \mathrm{~V}$ converter $) ; \eta=0.84$ and $I_{c h}=0.25 \mathrm{~A}(+5 \mathrm{~V}$ converter $) ;$ and $\eta=0.78$ and $I_{c h}=0.31$ $\mathrm{A}(+3.3 \mathrm{~V}$ converter $)$.

Once the output voltage, $V_{2}$, the input variables of the MPPT ( $I_{1}$ and $V_{1}$, i.e., the MPP), and the behavior of the MPPT ( $\eta$ and $\left.I_{\mathrm{ch}}\right)$ are known, the problem that needs to be solved is finding the correct value of the output current $I_{2}$. The following implicit equation defines this problem:

$$
I_{2}=\frac{V_{1} I_{1}}{V_{2}} \eta_{\max }\left(1-\exp \left(-\frac{I_{2}}{I_{\mathrm{ch}}}\right)\right) .
$$

As the equation from the solar panel 1-D/2-R equivalent circuit model, the above equation can be defined by using the left side of the Lambert W-function positive branch

$$
I_{2}=I_{\mathrm{ch}}\left(\lambda+W_{0}^{-}(-\lambda \exp (-\lambda))\right)
$$

where

$$
\lambda=\frac{V_{1} I_{1}}{V_{2} I_{\mathrm{ch}}} \eta_{\max }
$$




\section{LAMBERT W-FunCtion Simple EQuATIONS}

Once the problems in which the Lambert W-function needs to be accurately estimated were identified (see previous sections), they can be summarized as follows.

1) $1-D / 2-R$ equivalent circuit model

a) Solving equation (8) to obtain the value of $R_{s}$, by using the negative branch of the Lambert W-function, $W_{-1}$.

b) Solving equation (7) to obtain the output current $I$ in relation to the output voltage $V$ by using the right-side sub-branch of the positive branch of the Lambert Wfunction $\mathrm{W}_{0}{ }^{+}$.

2) El-Tayyan, Karmalkar and Haneefa, and Das explicit models: solving (15), (18), and (21) by using the negative branch of the Lambert W-function $W_{-1}$.

3) MPPT (based on dc-dc converters) performance: Solving equation (27) by using the left- sub-branch of the positive branch of the Lambert W-function $W_{0}{ }^{-}$.

A thorough review of the available literature was carried out, in order to obtain sufficiently large data to derive accurate mathematical expressions for the Lambert W-function within the appropriate $x$ variable range (where this function needs to be calculated).

The relevant data (i.e., the five parameters of the 1-diode/2resistors model $I_{\mathrm{pv}}, I_{0}, a, R_{s}$, and $R_{s h}$, the number of cells seriesconnected, $n$, the temperature in which the $I-V$ curve is measured or calculated $T$ and the four characteristic points $I_{\mathrm{sc}}, V_{\mathrm{oc}}, I_{\mathrm{mp}}$, and $V_{\mathrm{mp}}$ ), from 89 different photovoltaic devices (mostly solar panels), were found.

\section{A. Lambert W-Function for Solving the 1-D/2-R Equivalent Circuit Model Implicit Equation}

If we go to (7), this allows us to calculate the current for a variable $x$ that is written in relation to the aforementioned five parameters of the 1-diode/2-resistors model, the number of cells series-connected, the temperature and the output voltage $V$

$$
x=f\left(I_{\mathrm{pv}}, I_{0}, a, R_{s}, R_{s h}, n, T, V\right) .
$$

Bearing in mind that, when evaluating the performance of a photovoltaic device, two extremes of the above variable $x$ arise at short circuit $(V=0)$ and open circuit $\left(V=V_{\mathrm{oc}}\right)$ points, it is possible to define a characteristic interval for evaluating the Lambert $\mathrm{W}$-function in relation to (7). The values of the Lambert W-function $W_{0}{ }^{+}$calculated at each point (29) with the data from each photovoltaic device found in the available literature, at $V=0$ and $V=V_{\mathrm{oc}}$, are shown in Fig. 6. Based on these points, included in the bracket $\left[10^{-20}, 10^{-5}\right]$, the following approximation is proposed:

$$
\begin{aligned}
& W_{0}^{+}(x)=x \\
& -\exp \left(4.123 \cdot 10^{-6} \ln (x)^{2}+2.0001 \ln (x)+1.64 \cdot 10^{-4}\right) .
\end{aligned}
$$

The above equation has also been plotted in Fig. 7. It should be noted that this equation has $1.4 \%$ error for $x=0.1$, the accuracy being improved for lower values of $x$. For larger values of $x$ it is recommended to use the approximation proposed by Barry $e t$ al. [22] (see Appendix), as shown in Fig. 6.

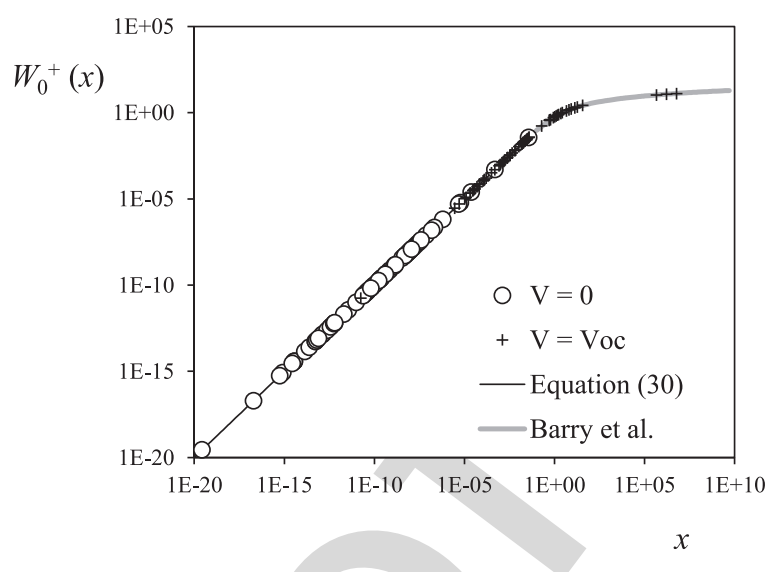

Fig. 6 Lambert W-function, $W_{0}+$ from (7) calculated at $V=0$ and $V=V_{\text {oc }}$ for the solar cells/solar panel data found in the available literature. The approximated (30) is also plotted in the graph.

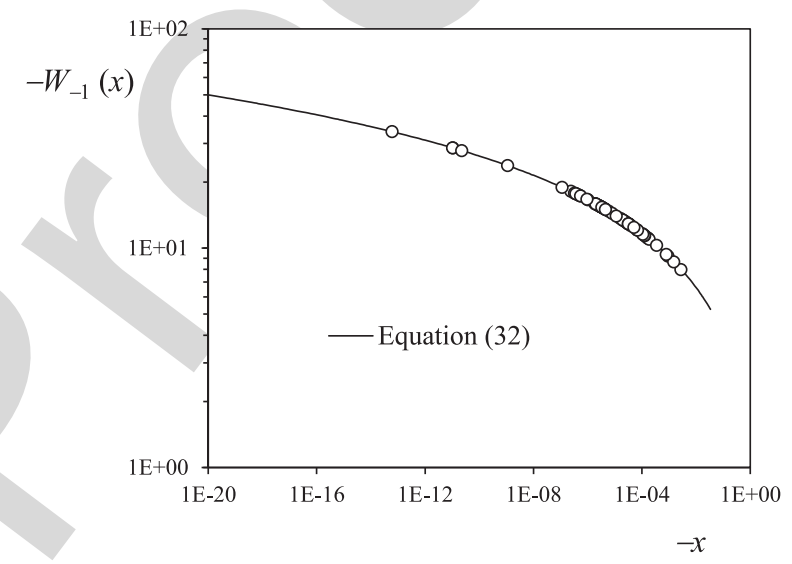

Fig. 7. Lambert W-function, $W_{-1}$ from (8) calculated for the solar cells/solar panel data found in the available literature (open circles). The approximated (32) is also plotted in the graph.

\section{B. Lambert W-Function for Solving the Series Resistor Implicit Equation From the Analytcal Solution of the 1-D/2-R Equivalent Circuit Model}

The negative branch of the Lambert $\mathrm{W}$-function, $W_{-1}$, allows the user to calculate the series resistor of the 1-diode/2-resistor model $R_{s}$ in relation to the characteristic points, the number of cells that are series-connected, the ideality factor and the temperature (8). Therefore, $W_{-1}$ is required to be evaluated at

$$
x=f\left(I_{\mathrm{sc}}, I_{\mathrm{mp}}, V_{\mathrm{oc}}, V_{\mathrm{mp}}, a, n, T\right) .
$$

In Fig. 7, the values of $W_{-1}$, calculated at the values of the above variable $x$ resulting from the solar cells and solar panel data found in the literature, are plotted. The bracket in which the Lambert $\mathrm{W}$-function $W_{-1}$ needs to be evaluated is $\left[-10^{-3}\right.$, $\left.-10^{-20}\right]$. The following simple expression is proposed for these estimations:

$$
\begin{aligned}
W_{-1}(x)= & 2.4978 \cdot 10^{-5} \ln (-x)^{3} \\
& +2.8111 \cdot 10^{-3} \ln (-x)^{2} \\
& +1.1299 \ln (-x)-1.4733 .
\end{aligned}
$$




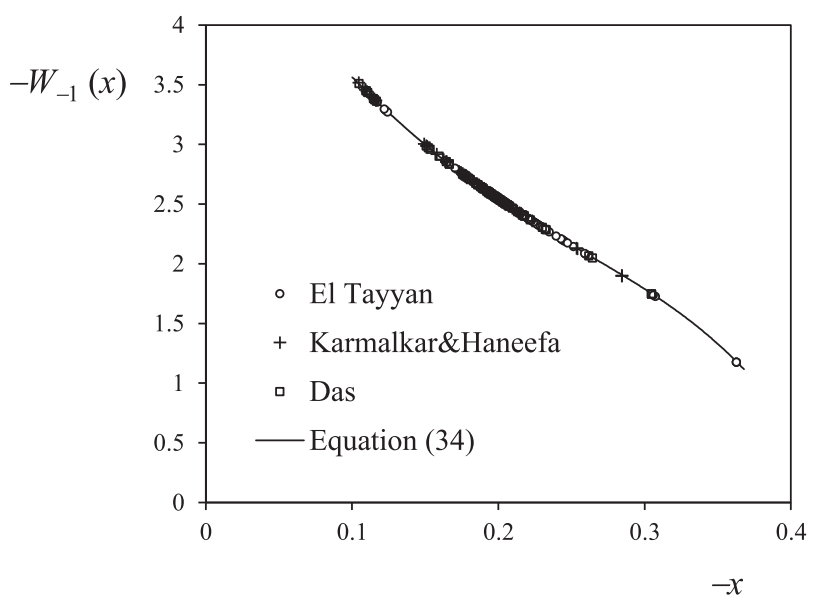

Fig. 8. Lambert W-function, $W_{-1}$ from (15), (18), and (21) calculated for the solar cells/solar panel data found in the available literature (open circles, crosses, and open squares). The approximated (34) is also plotted in the graph.

This equation is also plotted in Fig. 7. The maximum error in (32) was proven to be below $0.4 \%$, within the mentioned bracket.

\section{Lambert W-Function for Solving the Equations From El-Tayyan, Karmalkar and Haneefa, and Das Explicit Models}

With regard to the explicit models that need the Lambert W-function (15), (18), and (21), the values of this function are plotted in Fig. 8, in relation to the corresponding figures of variable $x$

$$
x=f\left(I_{\mathrm{sc}}, I_{\mathrm{mp}}, V_{\mathrm{oc}}, V_{\mathrm{mp}}\right)
$$

for each photovoltaic device found in the available literature. Based on these points, the following equation is proposed for the Lambert $\mathrm{W}$-function, $W_{-1}$, in the bracket $[-0.364,-0.1]$

$$
\begin{aligned}
& W_{-1}(x) \\
& =248.42 x^{4}+134.24 x^{3}+4.4258 x^{2}-14.629 x-4.9631 .
\end{aligned}
$$

The above equation has less than $1.6 \%$ error within the mentioned bracket.

\section{Lambert W-Function for Solving the Implicit Equation of} the MPPT Model

The left side of the Lambert W-function positive branch, required to solve the MPPT equation (see Section I-DD), needs to be evaluated at

$$
x=f\left(V_{1}, I_{1}, V_{2}, I_{\mathrm{ch}}, \eta_{\max }\right)
$$

along with (27) and (28). The following mathematical expressions are proposed to approach the aforementioned left side of the Lambert $\mathrm{W}$-function positive branch

$$
\begin{aligned}
W_{0}^{-}(x)= & x ; x \in\left[-8 \cdot 10^{-3}, 0\right] \\
W_{0}^{-}(x)= & 3.50621 x^{3}-0.7188 x^{2}+1.0104 x \\
& x \in\left[-2.15 \cdot 10^{-1},-8 \cdot 10^{-3}\right]
\end{aligned}
$$
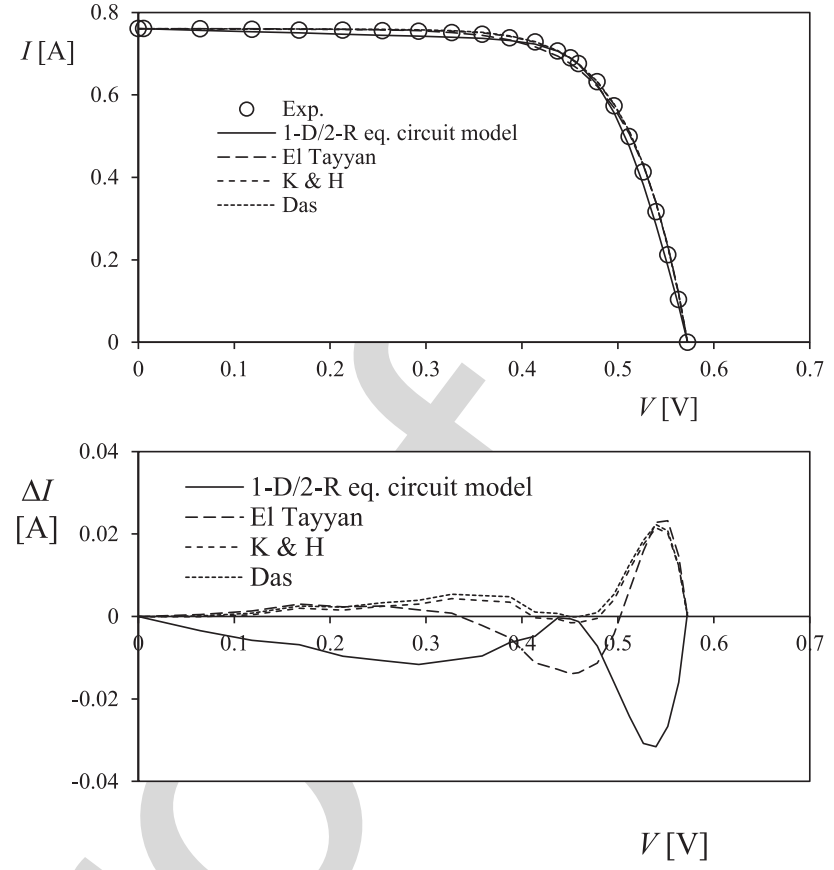

Fig. 9. RTC France solar cell [58]. 1-D/2-R equivalent circuit model and El Tayyan, Karmalkar and Haneefa, and Das explicit models fitted to the testing results (Exp.) (top). Error of the different models in relation to the testing results, $\Delta I=I-I_{\exp }$ (bottom).

TABLE I

NUMBER OF SERIES-CONNECTED CELlS AND CHARACTERISTIC POINTS FROM RTC France Solar CEll and PhotowatT PWP 201 Solar Panel

\begin{tabular}{|c|c|c|}
\hline & RTC France & $\begin{array}{c}\text { Photowatt } \\
\text { PWP 201 }\end{array}$ \\
\hline$n$ & 1 & 36 \\
\hline$I_{s c}[\mathrm{~A}]$ & 0.7605 & 1.0320 \\
\hline$I_{m p}[\mathrm{~A}]$ & 0.6894 & 0.9255 \\
\hline$V_{m p}[\mathrm{~V}]$ & 0.4507 & 12.493 \\
\hline$V_{o c}[\mathrm{~V}]$ & 0.5727 & 16.778 \\
\hline
\end{tabular}

$$
\begin{array}{r}
W_{0}^{-}(x)=1.56322\left(x+e^{-1}\right)^{\frac{1}{2.4}}-1 \\
x \in\left[-e^{-1},-2.15 \cdot 10^{-1}\right] .
\end{array}
$$

Equations (36)-(38) have an error below $0.8 \%, 0.82 \%$ and $1.86 \%$, respectively.

\section{RESULTS AND DISCUSSION}

\section{A. Modeling Solar Cells/Panels}

In order to check the expressions for the Lambert W-function obtained in the previous section, the well-known RTC France solar cell and Photowatt PWP 201 solar panel $I-V$ curves from Easwarakhanthan et al. [58] were used (see Figs. 9 and 10). Since the publication of this article, these curves have become the standard for checking photovoltaic performance models and parameter extraction procedures [59]-[69]. In Table I, the number of series-connected cells, $n$, and the characteristic points of both photovoltaic devices are included. 

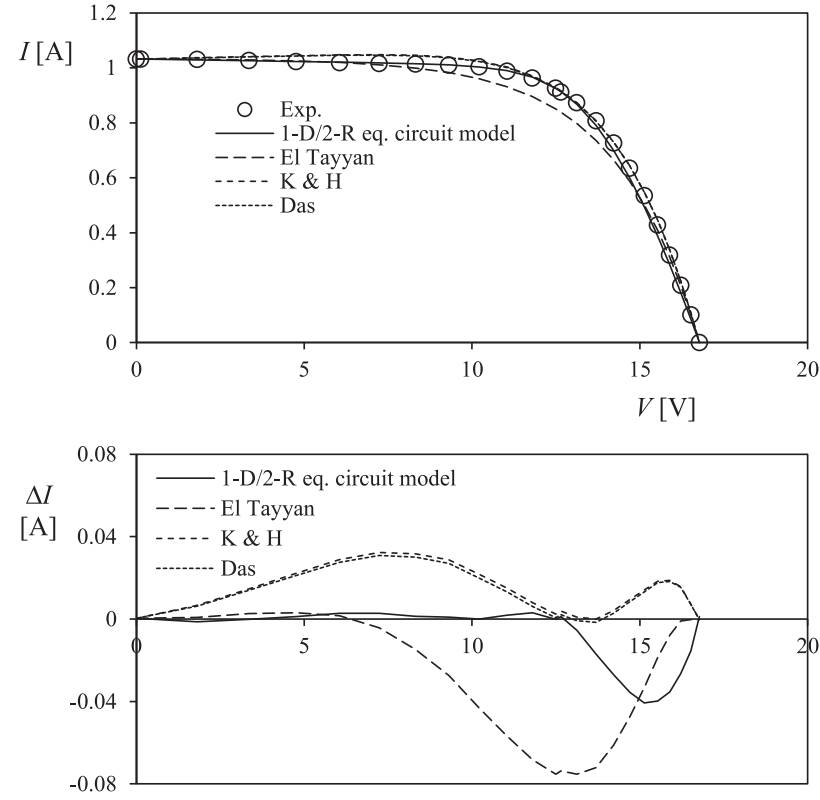

$V[\mathrm{~V}]$

Fig. 10. Photowatt PWP 201 solar panel [58]. 1-D/2-R equivalent circuit model and El Tayyan, Karmalkar and Haneefa, and Das explicit models fitted to the testing results (Exp.). Error of the different models in relation to the testing results, $\Delta I=I-I_{\exp }$ (bottom).

TABLE II 1-D/2-R EQuivalent Circuit Model Fitted to the RTC France Solar CELl $I$ - $V$ CURVE. PARAMETERS EXTRACTED IN THE PRESENT ARTICLE AND IN EASWARAKHANTHAN et $a l$. [58]

\begin{tabular}{|c|c|c|}
\hline & \multicolumn{2}{|c|}{ RTC France solar cell } \\
\hline & $\begin{array}{c}\text { Easwrakhanthan } \\
\text { et al. [58], [70] }\end{array}$ & $\begin{array}{c}\text { Present } \\
\text { work }\end{array}$ \\
\hline$a$ & 1.4837 & 1 \\
\hline$I_{p v}[\mathrm{~A}]$ & $7.608 \cdot 10^{-01}$ & $7.638 \cdot 10^{-01}$ \\
\hline$I_{0}[\mathrm{~A}]$ & $3.223 \cdot 10^{-07}$ & $2.692 \cdot 10^{-10}$ \\
\hline$R_{s}[\Omega]$ & $3.640 \cdot 10^{-02}$ & $6.977 \cdot 10^{-02}$ \\
\hline$R_{s h}[\Omega]$ & $5.376 \cdot 10^{+01}$ & $1.616 \cdot 10^{+01}$ \\
\hline RMSE $[\mathrm{A}]$ & $6.251 \cdot 10^{-03}$ & $1.401 \cdot 10^{-02}$ \\
\hline
\end{tabular}

In Tables II and III, the parameters related to the 1-D/2-R equivalent circuit model fitted to the mentioned $I-V$ curves are included. These parameters were first extracted by selecting a reasonable value for the ideality factor, $a=1$, and then by using (8) to (12), (6), (4), and (3), combined with (32), to solve the Lambert W-function in (6). Taking the extracted values of Tables II and III, (7) was solved with the help of the Lambert W-function in (30), to obtain the output current $I$ as a function of the output voltage $V$. The results have been included as a solid line in Figs. 9 and 10. It can be observed that the results obtained match those from testing. The error with regard to the testing results $\Delta I$ is plotted in the bottom graphs of these $1.7 \%$ (RTC) and $0.3 \%$ (PWP 201) for output voltages lower than $V_{\mathrm{mp}}$, and $4.6 \%$ (RTC) and 4.4\% (PWP 201) for output voltages larger than $V_{\mathrm{mp}}$. Additionally, it should be noted that, logically, figures, its maximum values being reduced in relation to $I_{\mathrm{mp}}$ :
TABLE III

1-D/2-R Equivalent Circuit Model FitTed to the Photowatt PWP 201 Solar Panel $I-V$ Curve. Parameters Extracted in the Present ARTICLE AND IN EASWARAKHANTHAN et al. [58]

\begin{tabular}{|c|c|c|}
\hline & \multicolumn{2}{|c|}{ Photowatt PWP 201 solar panel } \\
\hline & $\begin{array}{c}\text { Easwrakhanthan } \\
\text { et al. [58], [70] }\end{array}$ & $\begin{array}{c}\text { Present } \\
\text { work }\end{array}$ \\
\hline$a$ & 1.3458 & 1 \\
\hline$I_{p v}[\mathrm{~A}]$ & 1.0318 & 1.0358 \\
\hline$I_{0}[\mathrm{~A}]$ & $3.2876 \cdot 10^{-06}$ & $4.1626 \cdot 10^{-08}$ \\
\hline$R_{s}[\Omega]$ & 1.2057 & 1.9815 \\
\hline$R_{s h}[\Omega]$ & $5.4945 \cdot 10^{+02}$ & $5.4292 \cdot 10^{+02}$ \\
\hline RMSE $[\mathrm{A}]$ & $7.805 \cdot 10^{-03}$ & $1.799 \cdot 10^{-02}$ \\
\hline
\end{tabular}

TABLE IV

PARAMETERS OF El TAYYAN, KARMALKAR AND HANEEFA, AND DAS EXPLICIT Models, FitTed to RTC France Solar CELl AND PhOtowatt PWP 201 SOLAR PANEL EXPERIMENTAL DATA [58].

\begin{tabular}{|c|c|c|c|}
\hline \multicolumn{2}{|c|}{ Model parameters } & RTC & PWP \\
\hline \multirow{3}{*}{ El Tayyan } & $C_{1}$ & $7.6053 \cdot 10^{-01}$ & 1.03317 \\
\cline { 2 - 4 } & $C_{2}$ & $5.5678 \cdot 10^{-02}$ & 2.4751 \\
\cline { 2 - 4 } & RMSE $[\mathrm{A}]$ & $1.029 \cdot 10^{-02}$ & $4.092 \cdot 10^{-02}$ \\
\hline \multirow{2}{*}{$\begin{array}{c}\text { Karmalkar \& } \\
\text { Haneefa }\end{array}$} & $\gamma$ & $9.9322 \cdot 10^{-01}$ & 1.0422 \\
\cline { 2 - 4 } & $m$ & $1.0014 \cdot 10^{+01}$ & 6.9996 \\
\cline { 2 - 4 } & $\mathrm{RMSE}[\mathrm{A}]$ & $8.159 \cdot 10^{-03}$ & $1.649 \cdot 10^{-02}$ \\
\hline \multirow{3}{*}{ Das } & $k$ & $1.0021 \cdot 10^{+01}$ & 6.9669 \\
\cline { 2 - 4 } & $h$ & $4.2531 \cdot 10^{-03}$ & $-3.822 \cdot 10^{-02}$ \\
\cline { 2 - 4 } & RMSE $[\mathrm{A}]$ & $8.656 \cdot 10^{-03}$ & $1.556 \cdot 10^{-02}$ \\
\hline
\end{tabular}

the proposed approach is less precise than the numerical one proposed by Easwarakhanthan et al. (1986), showing a larger RMSE. Nevertheless, it can also be underlined that this larger error in the proposed approach can be reduced by optimizing the initial value of the ideality factor $a$ by an iterative process.

The results from the explicit models (El Tayyan, Karmalkar and Haneefa, and Das) applied to both the RTC France solar cell and the Photowatt PWP 201 solar panel, and solved with the proposed equations for the Lambert $\mathrm{W}$-function, are included in Figs. 9 and 10. A relevant match with the testing results can be observed (with the exception of the fitting of El Tayyan's method to the PWP 201 experimental data), with reasonably reduced values of RMSE (see Table IV). The current error $\Delta I$ in relation to the testing results, is plotted in the bottom graphs of Figs. 9 and 10 . As shown by the 1-D/2-R equivalent circuit model, the maximum errors in relation to $I_{\mathrm{mp}}$ are not large: $0.62 \%$ (RTC) and $3.5 \%$ (PWP 201) for output voltages lower than $V_{\mathrm{mp}}$, and $3.2 \%$ (RTC) and $2.1 \%$ (PWP 201) for output voltages larger than $V_{\mathrm{mp}}$. These results exclude those from El-Tayyan's model, whose maximum errors are approximately twice those from the other two explicit models. This poorer performance of El Tayyan's method has already been suggested [39].

Finally, it should be emphasized that the fairly accurate results obtained with the proposed methodology (i.e., the use of the Lambert W-Function when solving the 1-D/2-R equivalent circuit model and the explicit methods), are obtained by very simple calculations (in contrast with numerical methodologies) to solve the aforementioned models. This is the most important merit of the present article. 


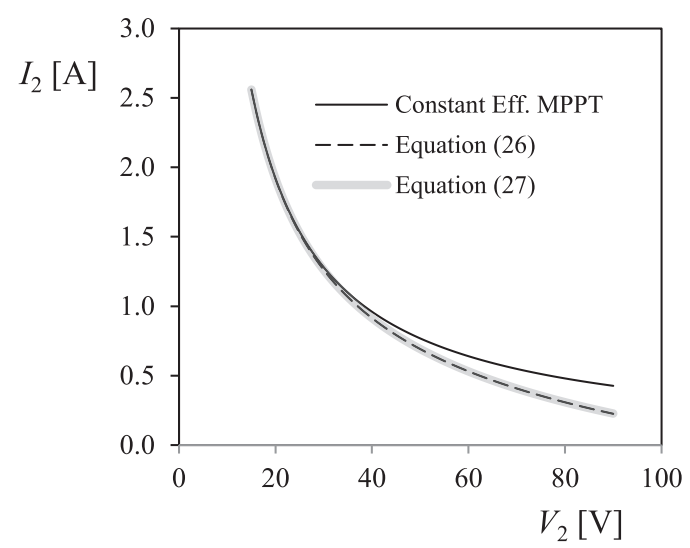

Fig. 11. Output current, $I_{2}$, from a MPPT system with the following characteristics: $V_{1}=\mathrm{V}, I_{1}=\mathrm{A}, \eta_{\max }=0.8$, and $I_{\mathrm{ch}}=0.3 \mathrm{~A}$ [see (24) to (28)], in relation to the output voltage $V_{2}$. The current, calculated by (26) and (27) is compared to the resulting one from a constant efficiency MPPT whose value is equal to $\eta_{\max }(24)$.

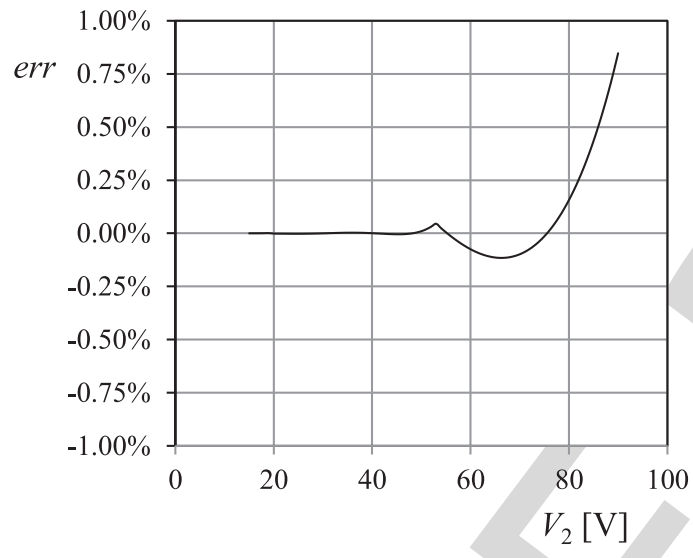

Fig. 12. Percentage error [err, see (39)] of the output current $I_{2}$ calculated by (27) [and the proposed approach to the left side of the Lambert W-function positive branch, (36) to (38)], with regard to the current calculated by solving (26). The error, err, is plotted in relation to the output yoltage $V_{2}$. (See also Fig. 11.)
Fig. 12 shows that the error related to equation (27), solved with the suggested approach to the Lambert $\mathrm{W}$-function defined by (36) to (38), is lower than $1 \%$.

\section{CONCLUSION}

The Lambert W-function has revealed itself to be a relevant tool for solving the implicit equations that arise when analyzing photovoltaic systems performance. However, working with this mathematical function can be a challenge as it is not represented by any direct equation.

In the present article, simple equations are successfully derived for the Lambert W-function in the following cases.

1) Direct calculation of the photovoltaic output current $I$ as a function of the output voltage $V$ by using the 1diode/2-resistor equivalent circuit model (with all the five parameters being well defined).

2) Calculation of the series resistor parameter $R_{s}$ from the 1-diode/2-resistor equivalent circuit model in relation to the characteristic points of the $I-V$ curve $\left(I_{\mathrm{sc}}, I_{\mathrm{mp}}, V_{\mathrm{oc}}\right.$, and $V_{\mathrm{mp}}$ ), the ideality factor $a$ the number of the seriesconnected cells of the photovoltaic device, and the thermal voltage $V_{T}$.

3) Calculation of the parameters from the explicit methods by El Tayyan, Karmalkar and Hannefa, and Das.

4) Calculation of the output current of a photovoltaic system composed of a solar panel and an MPPT based on a dcdc converter, when the efficiency of this maximum peak power tracking is modeled by a simple first-order system equation.

The proposed Lambert W-function equations were checked with well-known standard information from the RTC solar cell and the Photowatt PWP 201 solar panel $[I-V$ curves from Easwarakhanthan et al. (1986)]. The results obtained from fitting the 1-D/2-R equivalent circuit model (with an initial condition $a=1$ ) indicate a $4.6 \%$ maximum error (in relation to $I_{\mathrm{mp}}$ ). This is quite a relevant result, bearing in mind that this accuracy can be improved by optimizing the ideality factor $a$, and how easily it was obtained by using the proposed equations for the Lambert W-function. Additionally, the fitting of three explicit models to the aforementioned testing data was carried out with the derived equations. The results from the Karmalkar and Haneefa and Das models indicate a $3.5 \%$ maximum error (in relation to $I_{\mathrm{mp}}$ ). The results related to El Tayyan's model are less accurate, the lack of accuracy being related to the model itself.

The results regarding the Lambert $\mathrm{W}$-function equations when analyzing MPPT behavior, were also checked by a direct comparison with the numerical solution. The results obtained by the use of the procedure described in the present article have a maximum difference of $1 \%$ in relation to the numerical solution.

\section{APPENDIX}

Analytical approximation to the Lambert W-function proposed by Barry et al. [22]

$$
W_{0}^{-}(x)=-1+\frac{\sqrt{\varphi}}{1+\left(\left(N_{1} \sqrt{\varphi}\right) / N_{2}+\sqrt{\varphi}\right)}
$$

$$
\text { err }=\frac{I_{2, \text { eq.(27) }}-I_{2, \text { eq.(26) }}}{I_{2, \text { eq.(26) }}} \text {. }
$$


where

$$
\begin{aligned}
& \varphi=2(1+e x) \\
& N_{1}=\left(1-\frac{1}{\sqrt{2}}\right)\left(N_{2}+\sqrt{2}\right) \\
& N_{2}=3 \sqrt{2}+6-\frac{(2237+1457 \sqrt{2}) e-4108 \sqrt{2}-5764}{(215+199 \sqrt{2}) e-430 \sqrt{2}-796} \varphi \\
& W_{0}^{+}(x)=1.4586887 \ln \left(\frac{1.2 x}{\ln (2.4 x / \ln (1+2.4 x))}\right) \\
& -0.4586887 \ln \left(\frac{2 x}{\ln (1+2 x)}\right) \\
& W_{-1}(x)=-1-\sigma-5.95061\left(1-\frac{1}{1+f(\sigma)}\right)
\end{aligned}
$$

437 where

$$
\begin{aligned}
f(\sigma) & =\frac{0.23766 \sqrt{\sigma}}{1-0.0042 \sigma \exp (-0.0201 \sqrt{\sigma})} \\
\sigma & =-1-\ln (-x) .
\end{aligned}
$$

\section{ACKNOWLEDGMENT}

We are indebted to the Director of the IDR/UPM Institute, Prof. Angel Sanz-Andres, for his constant support in relation to all research activities carried out in this institution. We are indebted to Anna Maria Ballester-Bohn for her kind help in improving the text style. We are also grateful to the Reviewers, whose comments helped to improve this article.

\section{REFERENCES}

[1] L. Hernández-Callejo, S. Gallardo-Saavedra, and V. Alonso-Gómez, "A review of photovoltaic systems: Design, operation and maintenance," Sol. Energy, vol. 188, no. June, pp. 426-440, 2019.

[2] P. G. V. Sampaio and M. O. A. González, "Photovoltaic solar energy: Conceptual framework," Renew. Sustain. Energy Rev., vol. 74, pp. 590-601, Jul. 2017.

[3] M. H. Shubbak, "Advances in solar photovoltaics: Technology review and patent trends," Renew. Sustain. Energy Rev., vol. 115, 2019, Art. no. 109383.

[4] A. S. Sarkın, N. Ekren, and Ş. Sağlam, "A review of anti-reflection and self-cleaning coatings on photovoltaic panels," Sol. Energy, vol. 199, pp. 63-73, 2020.

[5] V. Muteri et al., "Review on life cycle assessment of solar photovoltaic panels," Energies, vol. 13, no. 1, 2020.

[6] M. Krebs-Moberg, M. Pitz, T. L. Dorsette, and S. H. Gheewala, "Third generation of photovoltaic panels: A life cycle assessment," Renew. Energy, vol. 164, pp. 556-565, 2021.

[7] A. M. Humada et al., "Modeling of PV system and parameter extraction based on experimental data: Review and investigation," Sol. Energy, vol. 199, pp. 742-760, 2020

[8] E. Roibás-Millán et al., "Implementation of concurrent engineering approach in MUSE (Master in space systems) master's degree in space engineering," in Proc. Athens, ATINER'S Conf. Paper Ser., 2018, pp. 1-19.

[9] J. B. Ballesteros, J. M. Alvarez, P. Arcenillas, E. Roibas, J. Cubas, and S. Pindado, "CDF as a tool for space engineering master's student collaboration and concurrent design learning," in Proc. 8th Int. Workshop Syst. Concurrent Eng. Space Appl., 2018.

[10] E. Roibás-Millán, F. Sorribes-Palmer, and M. Chimeno-Manguán, "The MEOW lunar project for education and science based on concurrent engineering approach," Acta Astronaut, vol. 148, pp. 111-120, Jul. 2018.
[11] E. Roibás-Millán, F. Sorribes-Palmer, M. Chimeno-Manguán, J. Cubas, and S. Pindado, "The Spanish contribution to the 1st ESA academy's concurrent engineering challenge: Design of the moon explorer and observer of water-ice (MEOW) mission," in Proc. 8th Int. Workshop Syst. Concurrent Eng. Space Appl., 2018.

[12] J. Cubas, A. M. Gomez-Sanjuan, and S. Pindado, "On the thermo-electric modelling of smallsats," in Proc. 50th Int. Conf. Environ. Syst., 2020, pp. $1-12$.

[13] F. J. Garcia-Sanchez, "On the convenience of teaching the lambert w function in science and engineering education curricula," researchgate," 2019. [Online]. Available: https://www.researchgate.net/publication/ 336666853 On the Convenience of Teaching the Lambert W Function_in_Science_and_Engineering_Education_Curricula

[14] F. Ghani, M. Duke, and J. Carson, "Numerical calculation of series and shunt resistances and diode quality factor of a photovoltaic cell using the Lambert W-function," Sol. Energy, vol. 91, pp. 422-431, 2013.

[15] S. xian Lun, S. Wang, G. hong Yang, and T. ting Guo, "A new explicit double-diode modeling method based on Lambert W-function for photovoltaic arrays," Sol. Energy, vol. 116, pp. 69-82, 2015.

[16] X. Gao, Y. Cui, J. Hu, G. Xu, and Y. Yu, "Lambert W-function based exact representation for double diode model of solar cells: Comparison on fitness and parameter extraction," Energy Convers. Manag., vol. 127, pp. 443-460, 2016.

[17] J. Polo et al., "Modeling I-V curves of photovoltaic modules at indoor and outdoor conditions by using the Lambert function," Energy Convers. Manag., vol. 195, pp. 1004-1011, 2019.

[18] M. Calasan, S. H. E. Abdel Aleem, and A. F. Zobaa, "On the root mean square error (RMSE) calculation for parameter estimation of photovoltaic models: A novel exact analytical solution based on lambert W function," Energy Convers. Manag., vol. 210, 2020.

[19] H. M. Ridha, "Parameters extraction of single and double diodes photovoltaic models using marine predators algorithm and Lambert w function," Sol. Energy, vol. 209, pp. 674-693, 2020.

20] D. Sarkar, A. Kumar, and P. K. Sadhu, "Different diode models comparison using lambert $\mathrm{w}$ function for extracting maximum power from BIPV modules," Int. J. Energy Res., pp. 1-12, 2020.

[21] D. Yousri, M. Abd Elaziz, D. Oliva, L. Abualigah, M. A. A. Al-qaness, and A. A. Ewees, "Reliable applied objective for identifying simple and detailed photovoltaic models using modern metaheuristics: Comparative study," Energy Convers. Manag., vol. 223, 2020.

[22] D. A. Barry, J. Y. Parlange, L. Li, H. Prommer, C. J. Cunningham, and F. Stagnitti, "Analytical approximations for real values of the Lambert W-function," Math. Comput. Simul., vol. 53, no. 1/2, pp. 95-103, 2000.

[23] J. Cubas, S. Pindado, and M. Victoria, "On the analytical approach for modeling photovoltaic systems behavior," J. Power Sources, vol. 247 pp. 467-474, Feb. 2014

[24] D. T. Cotfas, P. A. Cotfas, and S. Kaplanis, "Methods to determine the dc parameters of solar cells: A critical review," Renew. Sustain. Energy Rev., vol. 28, pp. 588-596, 2013.

[25] A. K. Tossa, Y. M. Soro, Y. Azoumah, and D. Yamegueu, "A new approach to estimate the performance and energy productivity of photovoltaic modules in real operating conditions," Sol. Energy, vol. 110, pp. 543-560, 2014.

[26] A. Ortiz-Conde, F. J. García-Sánchez, J. Muci, and A. Sucre-González, "A review of diode and solar cell equivalent circuit model lumped parameter extraction," FACTA Univ. Ser. Electron. Energ., vol. 27, pp. 57-102, 2014.

[27] D. Jena and V. V. Ramana, "Modeling of photovoltaic system for uniform and non-uniform irradiance: A critical review," Renew. Sustain. Energy Rev., vol. 52, pp. 400-417, 2015.

[28] V. J. Chin, Z. Salam, and K. Ishaque, "Cell modelling and model parameters estimation techniques for photovoltaic simulator application: A review," Appl. Energy, vol. 154, pp. 500-519, 2015.

[29] A. M. Humada, M. Hojabri, S. Mekhilef, and H. M. Hamada, "Solar cell parameters extraction based on single and double-diode models: A review,' Renew. Sustain. Energy Rev., vol. 56, pp. 494-509, 2016.

[30] H. Ibrahim and N. Anani, "Evaluation of analytical methods for parameter extraction of PV modules," Energy Procedia, vol. 134, pp. 69-78, 2017.

[31] E. Roibás-Millán et al., "Lambert W-function simplified expressions for photovoltaic current-voltage modelling," in Proc. 20th IEEE Int. Conf. Environ. Elect. Eng., 2020, pp. 1630-1635.

[32] E. Roibás-Millán, D. Alfonso-Corcuera, J. Cubas, J. M. Alvarez, S. Pindado, and A. M. Gomez-Sanjuan, "Performance analysis of photovoltaic systems: Research at IDR/UPM institute," in Proc. 20th IEEE Int. Conf. Environ. Elect. Eng., 2020, pp. 769-774. 
[33] J. Cubas, S. Pindado, and A. Farrahi, "New method for analytical photovoltaic parameter extraction," in Proc. 2nd Int. Conf. Renew. Energy Res. Appl., 2013, pp. 873-877.

[34] M. G. Villalva, J. R. Gazoli, and E. R. Filho, "Modeling and circuit-based simulation of photovoltaic arrays," in Proc. Braz. Power Electron. Conf., 2009, pp. 1244-1254.

[35] M. G. Villalva, J. R. Gazoli, and E. R. Filho, "Comprehensive approach to modeling and simulation of photovoltaic arrays," IEEE Trans. Power Electron., vol. 24, no. 5, pp. 1198-1208, May 2009.

[36] L. Peng, Y. Sun, Z. Meng, Y. Wang, and Y. Xu, "A new method for determining the characteristics of solar cells," J. Power Sources, vol. 227, pp. 131-136, Apr. 2013.

[37] J. Cubas, S. Pindado, and C. de Manuel, "Explicit expressions for solar panel equivalent circuit parameters based on analytical formulation and the Lambert W-Function," Energies, vol. 7, no. 7, pp. 4098-4115, Jun. 2014.

[38] S. Pindado and J. Cubas, "Simple mathematical approach to solar cell/panel behavior based on datasheet information," Renew. Energy, vol. 103, pp. 729-738, 2017.

[39] S. Pindado, J. Cubas, E. Roibás-Millán, F. Bugallo-Siegel, and F. SorribesPalmer, "Assessment of explicit models for different photovoltaic technologies," Energies, vol. 11, no. 6, 2018, Art. no. 1353.

[40] M. Oulcaid, H. E. Fadil, L. Ammeh, A. Yahya, and F. Giri, "One shape parameter-based explicit model for photovoltaic cell and panel," Sustain. Energy, Grids Netw., vol. 21, 2020, Art. no. 100312.

[41] J. Cubas, S. Pindado, and Á. Sanz-Andrés, "Accurate simulation of MPPT methods performance when applied to commercial photovoltaic panels," Sci. World J., vol. 2015, 2015, Art. no. 914212.

[42] M. Veerachary, T. Senjyu, and K. Uezato, "Voltage-based maximum power point tracking control of PV system," IEEE Trans. Aerosp. Electron. Syst., vol. 38, no. 1, pp. 262-270, Jan. 2002.

[43] R. Leyva, C. Alonso, I. Queinnec, A. Cid-Pastor, D. Lagrange, and L. Martínez-Salamero, "MPPT of photovoltaic systems using extremum Seeking control," IEEE Trans. Aerosp. Electron. Syst., vol. 42, no. 1, pp. 249-258, Jan. 2006.

[44] H. Dehbonei, S. R. Lee, and H. Nehrir, "Direct energy transfer for high efficiency photovoltaic energy systems part I: Concepts and hypothesis,' IEEE Trans. Aerosp. Electron. Syst., vol. 45, no. 1, pp. 31-45, Jan. 2009.

[45] M. Miyatake, M. Veerachary, F. Toriumi, N. Fujii, and H. Ko, "Maximum power point tracking of multiple photovoltaic arrays: A PSO approach,' IEEE Trans. Aerosp. Electron. Syst., vol. 47, no. 1, pp. 367-380, Jan. 2011

[46] M. B. Shadmand, M. Mosa, R. S. Balog, and H. A. Rub, "An improved MPPT technique for high gain DC-DC converter using model predictive control for photovoltaic applications," in Proc. IEEE Appl. Power Electron. Conf. Expo., 2014, pp. 2993-2999.

[47] S. Li, H. Liao, H. Yuan, Q. Ai, and K. Chen, "A MPPT strategy with variable weather parameters through analyzing the effect of the DC/DC converter to the MPP of PV system," Sol. Energy, vol. 144, pp. 175-184, 2017.

[48] S. Öztürk, P. Poşpoş, V. Utalay, A. Koç, M. Ermiş, and I. Çadırcı, "Operating principles and practical design aspects of all SiC DC/AC/DC converter for MPPT in grid-connected PV supplies," Sol. Energy, vol. 176, pp. 380-394, Dec. 2018.

[49] A. Raj, S. R. Arya, and J. Gupta, "Solar PV array-based DC-DC converter with MPPT for low power applications," Renew. Energy Focus, vol. 34 no. 00, pp. 109-119, 2020.

[50] E. Koutroulis and F. Blaabjerg, "Overview of maximum power point tracking techniques for photovoltaic energy production systems," Elect. Power Compon. Syst., vol. 43, no. 12, pp. 1329-1351, 2015.

[51] S. Lyden and M. E. Haque, "Maximum power point tracking techniques for photovoltaic systems: A comprehensive review and comparative analysis," Renew. Sustain. Energy Rev., vol. 52, pp. 1504-1518, 2015.
[52] L. Liu, X. Meng, and C. Liu, "A review of maximum power point tracking methods of PV power system at uniform and partial shading," Renew. Sustain. Energy Rev., vol. 53, pp. 1500-1507, 2016.

[53] D. Verma, S. Nema, A. M. Shandilya, and S. K. Dash, "Maximum power point tracking (MPPT) techniques: Recapitulation in solar photovoltaic systems," Renew. Sustain. Energy Rev., vol. 54, pp. 1018-1034, 2016.

[54] A. K. Gupta and R. Saxena, "Review on widely-used MPPT techniques for PV applications," in Proc. 1st Int. Conf. Innov. Challenges Cyber Secur., 2016, pp. 270-273.

[55] O. Singh and S. K. Gupta, "A review on recent MPPT techniques for photovoltaic system," in Proc. IEEMA Eng. Infin. Conf., 2018.

[56] M. Dhimish, "Assessing MPPT techniques on hot-spotted and partially shaded photovoltaic modules: Comprehensive review based on experimental data," IEEE Trans. Electron Devices, vol. 66, no. 3, pp. 1132-1144, Mar. 2019.

[57] I. Yadav, S. K. Maurya, and G. K. Gupta, "A literature review on industrially accepted MPPT techniques for solar PV system," Int. J. Elect. Comput. Eng., vol. 10, no. 2, pp. 2117-2127, 2020.

[58] T. Easwarakhanthan, J. Bottin, I. Bouhouch, and C. Boutrit, "Nonlinear minimization algorithm for determining the solar cell parameters with microcomputers," Int. J. Sol. Energy, vol. 4, no. 1, pp. 1-12, Jan. 1986.

[59] R. Chenouard and R. A. El-Sehiemy, "An interval branch and bound global optimization algorithm for parameter estimation of three photovoltaic models," Energy Convers. Manag., vol. 205, 2020, Art. no. 112400.

[60] A. A. Z. DIab, H. M. Sultan, T. D. Do, O. M. Kamel, and M. A. Mossa, "Coyote optimization algorithm for parameters estimation of various models of solar cells and PV modules," IEEE Access, vol. 8, pp. 111102-111140, 2020

[61] Q. Hao, Z. Zhou, Z. Wei, and G. Chen, "Parameters identification of photovoltaic models using a multi-strategy success-history-based adaptive differential evolution," IEEE Access, vol. 8, pp. 35979-35994, 2020.

[62] S. Li, Q. Gu, W. Gong, and B. Ning, "An enhanced adaptive differential evolution algorithm for parameter extraction of photovoltaic models," Energy Convers. Manag., vol. 205, 2020, Art. no. 112443.

[63] J. Liang et al., "Classified perturbation mutation based particle swarm optimization algorithm for parameters extraction of photovoltaic models," Energy Convers. Manag., vol. 203, 2020, Art. no. 112138.

[64] J. Liang et al., "Parameters estimation of solar photovoltaic models via a self-adaptive ensemble-based differential evolution," Sol. Energy, vol. 207, no. C, pp. 336-346, 2020.

[65] X. Lin and Y. Wu, "Parameters identification of photovoltaic models using niche-based particle swarm optimization in parallel computing architecture," Energy, vol. 196, 2020, Art. no. 117054

[66] W. Long, S. Cai, J. Jiao, M. Xu, and T. Wu, "A new hybrid algorithm based on grey wolf optimizer and cuckoo search for parameter extraction of solar photovoltaic models," Energy Convers. Manag., vol. 203, 2020, Art. no. 112243.

[67] R. Ben Messaoud, "Extraction of uncertain parameters of single and double diode model of a photovoltaic panel using salp swarm algorithm," Meas. J. Int. Meas. Confed., vol. 154, 2020, Art. no. 107446.

[68] G. Xiong, J. Zhang, D. Shi, L. Zhu, X. Yuan, and Z. Tan, "Winner-leading competitive swarm optimizer with dynamic Gaussian mutation for parameter extraction of solar photovoltaic models," Energy Convers. Manag., vol. 206, 2020, Art. no. 112450.

[69] D. Yousri, S. B. Thanikanti, D. Allam, V. K. Ramachandaramurthy, and M. B. Eteiba, "Fractional chaotic ensemble particle swarm optimizer for identifying the single, double, and three diode photovoltaic models' parameters," Energy, vol. 195, 2020, Art. no. 116979.

[70] K. Bouzidi, M. Chegaar, and A. Bouhemadou, "Solar cells parameters evaluation considering the series and shunt resistance," Sol. Energy Mater. Sol. Cells, vol. 91, no. 18, pp. 1647-1651, Nov. 2007. 